\title{
EL DESCENSO DE LA MORTALIDAD \\ EN LA ESPAÑA INTERIOR: ALBACETE Y CIUDAD \\ REAL, 1700-1895*
}

\section{DECREASE IN MORTALITY IN INNER SPAIN'S TERRITORIES: ALBACETE Y CIUDAD REAL, 1700-1895}

\author{
Vanesa Abarca, Enrique Llopis, \\ José Antonio Sebastián, \\ Universidad Complutense de Madrid, España; vabarca@ucm.es; llopisagelan@ccee.ucm.es; \\ jasebastian@ccee.ucm.es \\ José Ubaldo Bernardos y \\ Ángel Luis Velasco \\ Universidad Nacional de Educación a Distancia, Madrid, España; jbernardos@cee.uned.es; \\ alvelasco@madridsur.uned.es
}

Resumen. Durante el siglo XVIII y los dos primeros tercios del XIX, algunas provincias de la España interior, como Ávila y Guadalajara, no permanecieron totalmente ajenas al declive de la mortalidad que define la primera fase de la transición demográfica europea. ¿Sucedió algo parecido en otras áreas del interior caracterizadas por mayores niveles de desigualdad económica? Este artículo pretende despejar esa interrogante analizando los casos de las provincias de Albacete y Ciudad Real. Hemos usado la ratio óbitos-bautizados como proxy de la tasa bruta de mortalidad. La trayectoria de este indicador apunta a que la mortalidad también tendió a declinar a largo plazo en Albacete y Ciudad Real desde mediados del siglo XVIII, aunque tal caída se vio interrumpida por la enérgica y transitoria involución de dicha variable entre $1800 \mathrm{y}$ 1814 , y por el repunte de la misma en el intervalo 1865-1889.

Palabras clave: mortalidad; transición demográfica; España interior; siglos XVIII y XIX.

Abstract: During the 18th century and the first two thirds of the 19th, some of Spain's inland provinces, such as Avila and Guadalajara, were not completely exempt from the fall in the death rate which was a defining characteristic of the first phase of the demographic transition in Europe. Did something similar occur in other inland areas characterized by higher levels of inequality? This article aims to clear up this doubt through an analysis of the provinces of Albacete and Ciudad Real. We have used the

* Este trabajo ha sido financiado por los Proyectos de Investigación del Ministerio de Economía y Competitividad HAR2009-12436 y HAR2012-33810. Federico Rodríguez y Mercedes Díez han desempeñado estupendamente su cometido de asistentes de investigación. Vicente Pérez Moreda nos ha orientado en diversos asuntos. Los errores e insuficiencias deben imputarse en exclusiva a los autores.

Am. Lat. Hist. Econ., año 22, núm. 3, septiembre-diciembre, 2015, pp. 108-144 
deaths/baptisms ratio as a proxy of gross death rate. The path of this indicator suggests that the birth rate also tended to show a long term decline in Albacete and Ciudad Real from the mid-eighteenth century onwards, although this fall was halted through a noticeable regression of this variable between and its recovery in the period 1865-1889.

Key words: mortality; demographic transition; inner Spain; 18th and 19th centuries.

Fecha de recepción: 7 de febrero de 2014. Fecha de aceptación: 10 de noviembre de 2014.

\section{INTRODUCCIÓN}

$\mathrm{E}$ ste artículo cuestiona una visión arraigada en la historiografía internacional, la de la ausencia de España y, sobre todo, de sus regiones interiores, de la primera fase de la transición demográfica europea, caracterizada, desde mediados del siglo XVIII, por el declive de la mortalidad (Perrenoud, 2001; Schofield y Reher, 1991; Vallin, 1991). En un trabajo reciente hemos mostrado que en dos provincias del interior castellano, Ávila y Guadalajara, la mortalidad descendió entre los intervalos 1700-1749 y 1815-1864 (Llopis, Bernardos y Velasco, 2015). En ambas, los niveles de desigualdad económica eran menores que en otras más meridionales, como Ciudad Real y Albacete. ${ }^{1}$ Estas diferencias acentúan el interés del presente ensayo: ¿declinó la mortalidad entre los lapsos indicados, con similar intensidad en espacios del sur de la meseta socialmente más polarizados?

En cualquier caso, en el interior peninsular, el fenómeno distó del resto de Europa en varios aspectos relevantes: $a$ ) hacia 1750, la España interior partía de tasas de mortalidad relativamente elevadas en el contexto europeo y, a finales del siglo XIX, ese diferencial había aumentado; ${ }^{2} b$ ) la moderación de la mortalidad en menores de ocho años (los párvulos) resultó, en su seno, mucho más exigua, y $c$ ) ambas Castillas registraron un brutal, aunque transitorio, repunte de la mortalidad entre 1800 y 1814 , sin parangón en otros países europeos. En todo caso, hacia 1850 o 1880, tanto en Ávila y Guadalajara como probablemente en Ciudad Real y Albacete, la mortalidad era claramente inferior que en la primera mitad del siglo XVIII.

Este trabajo, centrado en las dos provincias castellanas más meridionales, pretende medir el descenso de la mortalidad en ellas entre las primeras

\footnotetext{
${ }^{1}$ En 1787, la ratio jornaleros y criados-labradores era de 1.79 en Ávila y de 0.83 en Guadalajara; en cambio, ascendía a 2.59 en Albacete y a 2.86 en Ciudad Real. Instituto Nacional de Estadística (1987, pp. 1046, 1318 y 1374).

${ }^{2}$ Entre 1740 y 1754, la tasa de mortalidad francesa, de $38.6 \%$, era parecida a la española. En cambio, para $1850-1864$, aquella había caído a $23.4 \%$, mientras que esta rondaba $30 \%$, siendo aún más alta en la España interior. Chesnais (1986, pp. 500-503 y 526-529) y Pérez (1984, p. 27).
} 
décadas del setecientos y las postreras del ochocientos, estudiar su trayectoria en ese periodo, y comprobar el papel en la misma de sus componentes, la mortalidad adulta, la párvula, la ordinaria y la catastrófica.

En el interior peninsular, Ciudad Real y, particularmente, Albacete destacan por su dinamismo demográfico en los siglos XVIII y XIX; entre $1700-1709$ y $1855-1864$, el número de bautizados creció a una tasa de $0.42 \%$ en la primera y de $0.63 \%$ en la segunda, frente al crecimiento de $0.29 \%$ en Burgos, 0.32\% en Guadalajara y 0.52\% en Ávila (Abarca, 2012; Base de datos del Grupo Complutense de Historia Económica Moderna). Los espacios manchegos más meridionales habían sido débilmente colonizados antes de 1700; de ahí las posibilidades roturadoras que permitieron sustentar un sensible incremento demográfico durante bastante tiempo.

La organización del presente texto es la habitual. El segundo apartado, a continuación, se dedica a fuentes y metodología; en el tercero se ofrecen los resultados obtenidos sobre la trayectoria de la mortalidad (general, párvula, adulta, ordinaria y catastrófica) en Albacete y Ciudad Real, y se comparan con los de otras provincias castellanas; en el cuarto se plantean algunas hipótesis sobre las causas del declive en dicha variable durante la segunda mitad del siglo XVIII y después de 1815 , y, en el quinto, se sintetizan las principales conclusiones de la investigación.

\section{FUENTES Y MÉTODOS}

La base factual de este trabajo la hemos extraído de los censos de población de 1752, 1787, 1857, 1860 y 1887, y, más aún, de los libros de bautismos y defunciones de 28 localidades, catorce de Ciudad Real y catorce de Albacete. Se trata de fuentes muy conocidas, cuyos defectos y virtudes han sido expuestos en numerosos trabajos (Gurría, 2004, pp. 27-33; Lanza, 1991, pp. 54-60; Llopis, Sebastián y Velasco, 2012, pp. 15-16 y 19-25; Piquero, 1991, pp. 51-57; Saavedra, 1985, pp. 57-59). No obstante, conviene insistir en ciertos problemas que plantea su utilización.

Pese a la universalidad del bautismo en la España de la época, los libros de bautizados no incluyen a todos los nacidos: falta la mayoría de los que murieron antes de llegar a la pila bautismal. Es imposible ofrecer cifras precisas sobre su número y su proporción sobre el total, dado el escaso rastro documental que dejó su paso. Cabe hacer estimaciones sobre el porcentaje de neonatos que fallecían en los primeros días de vida (Ramiro, 1998; Sanz, 1997), ${ }^{3}$ ya que lo más influyente en el peso relativo de los registros omitidos

\footnotetext{
${ }^{3}$ A partir de las tablas de mortalidad de los menores de un mes elaboradas por dichos autores para Madrid y Toledo en el siglo XIX.
} 
por tal motivo en los libros de bautizados era el plazo promedio entre nacimiento y bautismo; ahora bien, este varió en el espacio y en el tiempo. ${ }^{4}$ Hasta que no conozcamos con detalle su evolución, no podremos estimar con suficiente fundamento la proporción de nacidos no registrados y sus cambios durante los siglos XVIII y XIX. Es por ello que hemos decidido no retocar, por ahora, las cifras de bautizados. Según parece, el plazo citado fue reduciéndose ya en el setecientos, sobre todo en su segunda mitad, con lo que el diferencial nacidos-bautizados también tuvo que descender. Reconocemos que ello supone un sesgo a favor de la hipótesis que aquí mantenemos: la caída en el largo plazo de la tasa bruta de mortalidad. No obstante, considérese que este se compensa, en su totalidad o en parte, con otro de signo contrario: el subregistro de defunciones, sobre todo de menores de ocho años, que también parece haber menguado con el paso del tiempo.

El principal problema que plantean los libros de defunciones de muchas parroquias en Albacete y Ciudad Real es que el registro sistemático de los óbitos de párvulos no comienza hasta el decenio de 1740 o fechas posteriores y que, después, la sospecha de subregistro vuelve a aflorar en distintos periodos, lo que no es exclusivo de ambas provincias manchegas (Arizcun, 1988, pp. 174-177; Bernat y Badenes, 1988, pp. 538-539; Blanco, 1999, pp. 60-61; Lanza, 1991, pp. 62-65; Lázaro y Gurría, 1989, pp. 13-16; Llopis, Bernardos y Velasco, 2015; Pérez, 1980, pp. 29-44; Piquero, 1991, pp. 54-57). Y es que la calidad de las relaciones de finados es muy desigual entre parroquias distintas, entre los libros de una misma parroquia e, incluso, entre diferentes tramos de un mismo libro.

Para minimizar este inconveniente a la hora de escoger series de difuntos que configuren una muestra fiable, hemos diseñado un test de validación. Este parte de lo demostrado por numerosos estudios sobre la España interior: que durante largas fases de los siglos XVII, XVIII y XIX, los párvulos suponían cerca de 50\% del total de defunciones (Blanco, 1999, p. 158; Pérez, 1980, pp. 162-163), ${ }^{5}$ siendo muy poco verosímil que esa proporción, aunque se alejase en ocasiones del referido umbral, se situase por debajo de $40 \%$ en tramos de 20 o más años. Por lo tanto, las series de finados construidas no son validadas si los párvulos no superan casi siempre, en intervalos de 20 años, $40 \%$ del total de finados. ${ }^{6}$ Adicionalmente,

${ }^{4}$ En cinco localidades de Ciudad Real, dicho intervalo fue, en promedio, de 9.3 días en 1705 , de 8.6 en 1730, de 9.3 en 1751, de 6.4 en 1775 , de 2.5 en 1801, de 1.3 en 1825 , de 1.2 en 1851 y de 1.7 en 1875. En cinco pueblos albaceteños, ascendió a 10.6 días en 1705 , a 8.3 en 1730, a 7.7 en 1851, a 5.1 en 1775, a 3.0 en 1801, a 2.1 en 1825 , a 2.7 en 1851 y a 2.2 en 1875 . p. 175).

${ }^{5}$ En la España húmeda ese porcentaje era inferior (Arizcun, 1988, p. 176; Piquero, 1991,

${ }^{6}$ Una crisis de mortalidad particularmente intensa que afectase mucho más a la población adulta que a la infantil podía originar que dicho porcentaje se situase transitoriamente por debajo 
pese a cumplir este criterio cuantitativo, algunas series pueden desecharse por otros motivos. Primero, por presentar alzas espectaculares del citado porcentaje entre dos tramos prolongados, como ocurre con las pocas localidades albaceteñas en las que el registro sistemático de difuntos menores de ocho años se inicia antes de $1700 .{ }^{7}$ Segundo, si presentan pesos relativos de párvulos (o ratios óbitos de párvulos-bautizados) en lapsos de 20 o más años muy inferiores al patrón observado en los demás núcleos de la provincia, en especial si, además, existen diferencias marcadas entre los perfiles evolutivos. Tercero, si nuestro atento examen de los libros de difuntos detecta otras irregularidades que así lo aconsejen. ${ }^{8}$

En síntesis, utilizamos un test de validación con un criterio taxativo de carácter cuantitativo y una reevaluación complementaria, cuya aplicación obliga a desechar bastantes series locales de finados, lo que supone más tiempo y esfuerzo investigador. Pero, a cambio, mejora notablemente el material informativo al minimizar el subregistro de párvulos.

Sólo dos pueblos de Albacete (El Bonillo y La Gineta) y tres de Ciudad Real (Ballesteros de Calatrava, Malagón y Socuéllamos) incluyen registros de párvulos para 1700-1895 y han superado el test de validación en todos los tramos de sus series. Con muestras tan exiguas, hemos preferido renunciar al estudio de la mortalidad general y párvula en la primera mitad del siglo XVIII. Para 1750-1864, en cambio, hemos construido nueve series locales para Albacete y once para Ciudad Real que sí satisfacen nuestro test (véase mapa 1). Durante ese siglo largo, los párvulos supusieron 54.3\% del total de finados en la primera muestra y $53.7 \%$ en la segunda, y en casi todos sus tramos de 20 años ese porcentaje se situó en torno a 50\%. En definitiva, hemos sacrificado el estudio de la mortalidad párvula y de la general en una fase, 1700-1750, pero hemos logrado minimizar el subregistro de párvulos en nuestras series.

En cuanto a las defunciones de adultos, que suelen plantear menos problemas, un estudio detenido de la ratio óbitos de adultos-bautizados en periodos de 20 años no ha evidenciado anomalías de relieve tocantes, por ejemplo, a un posible subregistro de pobres o intestados.

Junto al test de validación descrito, hemos empleado otros criterios en la selección de los pueblos integrantes de las muestras de ambas provincias. Estos atañen al tamaño de las mismas respecto de sendas poblaciones provinciales (suficiente, parecido y que no variase mucho con el paso del

de 40\% en algún tramo de 20 años. Así ocurrió en numerosas áreas castellanas a raíz de la crisis de 1803 a 1805 .

${ }^{7}$ En Elche de la Sierra, Lezuza, Nerpio y Tobarra, la referida proporción aumentó más de diez puntos entre la primera y la segunda mitad del setecientos.

${ }^{8}$ Saavedra (1996) ha subrayado la importancia del criterio del investigador a la hora de determinar el grado de fiabilidad de los registros de defunciones. 


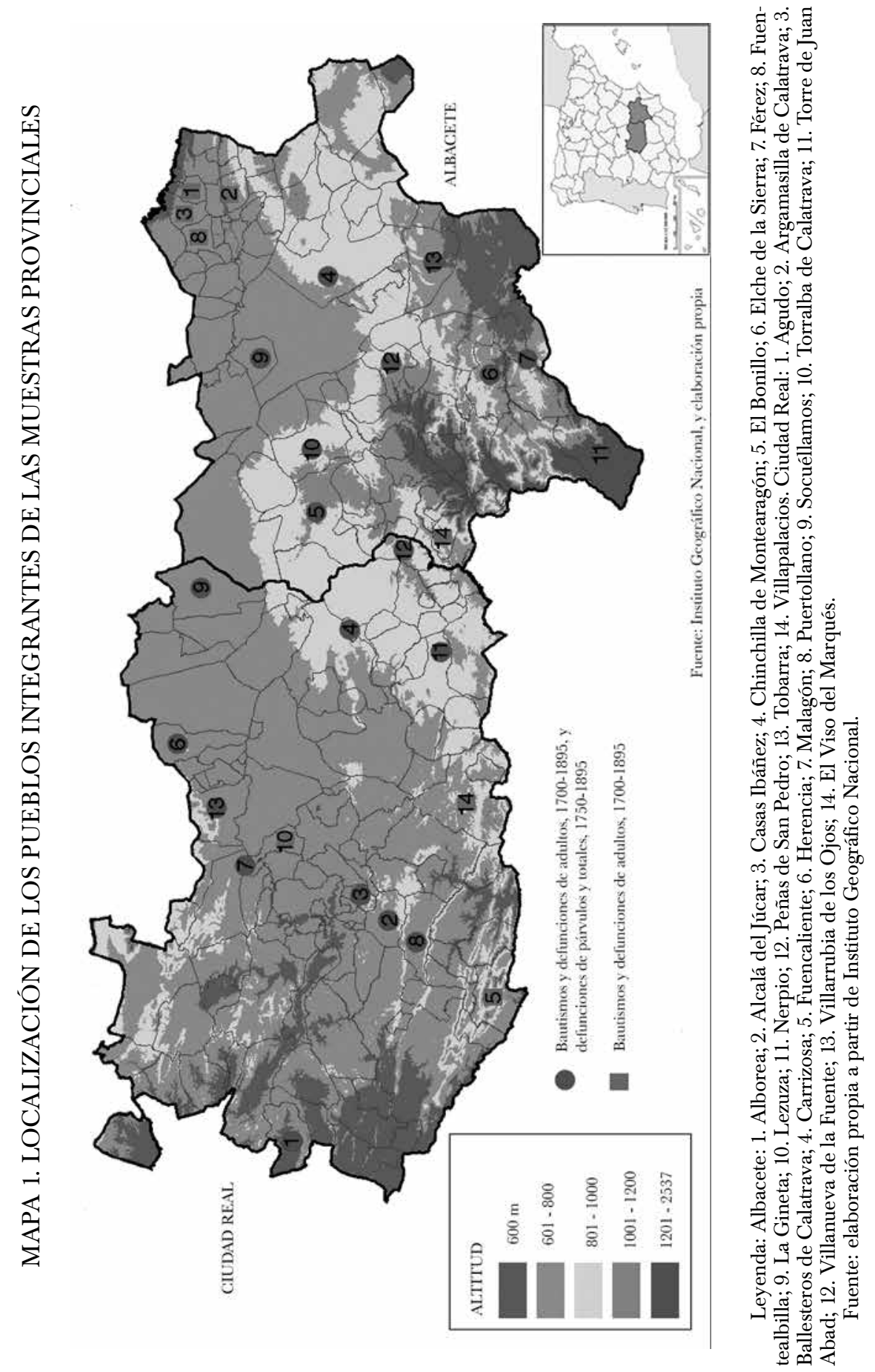


tiempo) y a su composición: localidades con registros de bautismos y óbitos, al menos de adultos, prácticamente completos de 1700 a 1895, con un reparto equilibrado por la geografía de Ciudad Real y Albacete, y con una distribución por tamaño similar a la de la provincia respectiva.

En realidad, el margen de elección ha sido escaso porque el número de localidades con registros de óbitos y de bautismos sin huecos, que permitan formar series de defunciones de párvulos de calidad, es muy reducido en ambas provincias. Para cada una, hemos formado una muestra de catorce localidades (véase mapa 1). En Albacete, en todas ellas cabe estudiar la mortalidad adulta entre 1700 y 1895 , pero la párvula y la general sólo pueden analizarse en nueve, y únicamente para 1750-1895. En Ciudad Real sucede algo parecido, con la diferencia de ser once las localidades que permiten examinar la mortalidad párvula y general de 1750 a 1895 .

Pese a las reducidas posibilidades de elección, ambas muestras cumplen de manera satisfactoria los restantes criterios. Por un lado, ambas tienen un tamaño suficiente: las más pequeñas, de nueve y once localidades, albergaban 17.7 y 13.5\% de la población de Albacete y Ciudad Real, respectivamente en 1787; las más grandes, de catorce localidades en sendos casos, 23.1 y 18.1\%, en igual orden (Instituto Nacional de Estadística, 1987, pp. 1281-1282 y 1341-1342). A nuestro juicio, estos porcentajes están muy por encima de los umbrales necesarios para estudios de carácter provincial. Además, el peso relativo de todas las muestras en las respectivas poblaciones provinciales se mantuvo bastante estable entre 1752 o 1787 y $1887^{9}$

Por otro lado, las dos muestras logran una representación territorial bastante satisfactoria de ambas provincias (véase mapa 1).

Por último, también cumplen aceptablemente el postrero criterio señalado. Sus distribuciones por tamaño de los núcleos incluidos son semejantes a las de sus respectivas provincias. En 1787, el tamaño medio de las muestras más grandes era de 2213 habitantes en Albacete y de 2214 en Ciudad Real; el del total de localidades, de 1680 en una y de 2017 en la otra (Instituto Nacional de Estadística, 1987, pp. 1281-1282 y 1341-1342). Los pueblos medianos están algo sobrerrepresentados en ambos territorios, al contrario de los pequeños y los muy grandes. ${ }^{10}$

En suma, consideramos que la calidad de las muestras es alta y que las conclusiones extraídas de su estudio pueden extenderse a las respectivas provincias.

${ }^{9}$ En Albacete, la muestra más pequeña reunía 17.7\% de la población provincial en $1787,17.3 \%$ en 1857 y $16.5 \%$ en 1887 ; la más grande, $23.1,21.4$ y $21.2 \%$. La más pequeña de Ciudad Real, 13.3, 13.4 y 13.4\% en 1752, 1857 y 1887, respectivamente; la más grande, 17.7, 17.1 y 16.8 por ciento.

${ }^{10}$ Ello es así porque en los núcleos pequeños la calidad de los registros sacramentales suele ser peor, mientras que en los muy grandes, al contar con varias parroquias, a menudo faltan registros de bautismos y/o de difuntos. 
Para medir los niveles provinciales de mortalidad utilizamos dos procedimientos distintos pero complementarios. El primero es el tradicional: el cálculo, en el entorno de los vecindarios y censos más fiables, de tasas brutas de mortalidad. Hemos empleado promedios de defunciones de nueve años centrados en la fecha del recuento correspondiente (1752 -sólo para Ciudad Real-, 1787, 1857, 1860 y 1887). Un análisis crítico de tales recuentos lo realizan Llopis, Sebastián y Velasco (2012, pp. 19-25). Ellos plantean tres problemas relevantes: $a$ ) incluye muy pocos cortes temporales; $b$ ) no cubre dos largos periodos, la primera mitad del setecientos y el situado entre 1787 y 1857 , y $c$ ) cuatro de los cinco recuentos se efectuaron después o durante importantes crisis demográficas en una o en las dos provincias, ${ }^{11}$ por lo que las tasas de mortalidad calculadas resultan anormalmente elevadas e impiden apreciar bien la trayectoria de dicha variable entre mediados del siglo XVIII y las décadas centrales del XIX.

Es por ello que hemos recurrido al segundo procedimiento, la construcción de una variable proxy, ratios defunciones-bautizados en periodos de quince, 20, 25 o 50 años presentadas en ventanas móviles. ${ }^{12} \mathrm{Si}$ las tasas de natalidad, a escala provincial y en promedios de unos 20 años, hubiesen variado poco, tales ratios constituirían un buen indicador (horizontal) del perfil, a mediano y largo plazos, de las tasas brutas de mortalidad. Trabajando con muestras provinciales amplias y con promedios de $20 \mathrm{o}$ 25 años, consideramos que este supuesto se cumple, ya que las fuertes oscilaciones a corto plazo de las tasas de natalidad se atenúan, lo que es congruente con la ausencia de cambios sustanciales en la estructura de edades y las pautas demográficas de las familias castellanas en el siglo XVIII y los dos primeros tercios del XIX (Llopis y Pérez, 2003, p. 126). Al respecto, la estabilidad en el largo plazo de las tasas de natalidad resulta significativa: las hemos calculado con promedios de bautismos de sólo nueve años y para fechas censales, en su mayoría, de mortalidad relativamente elevada (véase cuadro 1$).{ }^{13}$

${ }^{11}$ A resultas, sobre todo, de las sobremortalidades de finales de la década de 1740 y de comienzos de la de 1750, de la epidemia de paludismo de 1786-1787 y del cólera de 1855 .

${ }^{12} \mathrm{El}$ intervalo de quince años sólo lo empleamos para la década y media inicial del siglo XIX, una fase con una demografía y una economía muy distintas de las de las fases precedentes y posteriores. Las ventanas móviles son una variante de las medias móviles, según la cual a cada año de la serie de ratios defunciones/bautizados se le adjudica el promedio del periodo de quince, 20, 25 o 50 años que se inicia con él.

${ }^{13}$ La de Albacete de 1787 nos parece demasiado alta. Esta provincia registró una intensa colonización en el siglo XVIII, y la continua formación de nuevas aldeas pudo dificultar las operaciones censales en algunas comarcas. Resulta verosímil, por ello, que el número de habitantes de varias localidades esté sesgado a la baja y que la tasa de natalidad provincial fuese menor y, por consiguiente, más cercana a las de 1857 y 1887. 
CUADRO 1. TASAS DE NATALIDAD EN MUESTRAS DE LOCALIDADES DE SIETE PROVINCIAS, AÑOS 1752, 1787, 1857 Y 1887 (EN \%0)

\begin{tabular}{lrrcrrrr}
\hline & & & & & \multicolumn{3}{c}{ Ciudad } \\
Año & Burgos & Avila & Guadalajara & La Rioja & Soria & Real & Albacete \\
1752 & 43.1 & 43.4 & 40.0 & 40.9 & 44.6 & 42.1 & - \\
1787 & 45.2 & 42.8 & 39.8 & 42.1 & 44.9 & 42.9 & 46.3 \\
1857 & 44.5 & 41.9 & 40.9 & 40.6 & - & 42.7 & 43.5 \\
1887 & - & 42.1 & 39.7 & 40.2 & - & 42.7 & 42.0 \\
\hline
\end{tabular}

Fuente: elaboración propia con base en Libros de bautismos; archivos diocesanos de Burgos, Ávila, Sigüenza, Burgo de Osma, Soria, Ciudad Real, y https://familysearch.org; Abarca (2012); Libros de lo Personal de las Respuestas Particulares del Catastro de Ensenada de las provincias de Guadalajara, Burgos, Ávila y Ciudad Real; Martín (1985); Archivo de la Diputación de Burgos; Archivo Histórico Provincial de Ávila y https://familysearch.org; Llopis, Sebastián y Velasco (2012, p. 21); Gurría (2004, p. 44); Base de Datos del Grupo Complutense de Historia Económica Moderna; Camarero (1994); Instituto Nacional de Estadística (1987; 1989a y 1989b); Censo de 1857 (1858); Nomenclátor de 1857 (1858); Censo de 1887 (1891).

En casi todas las provincias analizadas, la tasa de natalidad era algo más baja hacia 1857 que hacia 1787. Es probable, pues, que las ratios defunciones-bautizados infravaloren un tanto el retroceso de la tasa bruta de mortalidad entre la segunda mitad del siglo XVIII y mediados del XIX. El sesgo, en este caso, actuaría en contra de las tesis que aquí defendemos.

Pero en las tres primeras décadas del siglo XIX, la relativa estabilidad a mediano y largo plazos de las tasas de natalidad se quebró transitoriamente en la España interior. En los quince primeros años del ochocientos, las pésimas cosechas de 1802 a 1805, las graves epidemias de 1803 a 1805 , 1809 y 1812 a 1813, y el desastroso impacto de la guerra de Independencia (Pérez, 1980, pp. 375-390, y 2010a, pp. 305-332), presionaron a la baja la natalidad y la nupcialidad. Al contrario, desde 1815 los matrimonios antes pospuestos, los huecos demográficos generados por las crisis previas, las masivas roturaciones de tierras desde los años de la guerra y, al poco, el prohibicionismo cerealista, propiciaron el estallido de un boom de la natalidad y de la nupcialidad que se prolongó hasta finales de la década de 1820 (Llopis, 2010, pp. 339-355, y 2013, pp. 116-129). Es probable, pues, que las ratios óbitos-bautizados sobrevaloren el alza de la mortalidad entre 1800 y 1814 y exageren algo su caída entre 1815 y 1829.

Los flujos migratorios alteraban las pirámides demográficas y los niveles de mortalidad. Protagonizados mayoritariamente por jóvenes entre 
quince y 35 años, provocaban en las regiones de origen el envejecimiento de la población y el alza de la tasa de mortalidad. Por consiguiente, en áreas de persistente emigración, las ratios difuntos-bautizados exageran las elevaciones (e infravaloran las caídas) de la mortalidad.

Albacete y Ciudad Real arrojan relevantes saldos migratorios negativos a finales del siglo XVIII y en la primera mitad del XIX. En las muestras más pequeñas de ambas provincias, el crecimiento vegetativo fue muy superior al de la población, absorbiendo la emigración neta 37.0\% de aquel en la primera y $39.6 \%$ en la segunda. ${ }^{14}$ Por lo tanto, en ambos territorios el retroceso de las ratios defunciones-bautizados después de 1815 subestima algo la caída de la mortalidad. Esto es, si en ambas provincias las pirámides de población no hubiesen sido modificadas por la notable emigración, el declive de las ratios finados-bautismos habría sido mayor que el observado. En consecuencia, nuestro indicador tiende a minusvalorar el alcance de la disminución real de la mortalidad entre 1750-1799 y 1815-1864. De 1857 a 1887 el panorama migratorio varió: en Albacete, entre esas dos fechas, el crecimiento de la población y el vegetativo fueron prácticamente idénticos; en Ciudad Real, la emigración neta absorbió 18.2\% del crecimiento vegetativo, porcentaje muy inferior al registrado en la fase precedente.

En suma, según las fuentes disponibles y a la luz de la relativa estabilidad de las tasas provinciales de natalidad a largo plazo, consideramos que la ratio defunciones-bautizados constituye una de las mejores vías de aproximación a la trayectoria de la mortalidad en el largo plazo en los distintos territorios castellanos durante el siglo XVIII y los dos primeros tercios del XIX.

\section{EL MODERADO DESCENSO DE LA MORTALIDAD EN LA MESETA MERIDIONAL}

¿Qué aconteció con la mortalidad en Albacete y Ciudad Real en las dos centurias que precedieron al inicio de la transición demográfica en las postrimerías del siglo XIX?

En un trabajo de síntesis sobre España, Reher (2001) señaló que la mortalidad catastrófica se redujo notablemente y que la ordinaria también disminuyó en el ochocientos (p. 489). Las evidencias reunidas en esta investigación, centradas en los territorios de Albacete y Ciudad Real, corroboran parcialmente dichas hipótesis y apuntan a que el comienzo del

${ }^{14}$ De 1787 a 1857, el saldo vegetativo fue de 17599 individuos en Albacete y de 15584 en Ciudad Real; por su parte, los respectivos crecimientos demográficos alcanzaron 11088 y 9408 habitantes. 
declive de la mortalidad en las citadas provincias de la meseta meridional debe retrotraerse a la segunda mitad del siglo XVIII.

El primer método de reconstrucción de la evolución de la mortalidad, el establecimiento de tasas de mortalidad en el entorno de los censos más dignos de confianza, afronta el escollo, como indicamos, de que los recuentos de 1752 y de 1787 se realizasen en fases en las que se registraron dos o tres años de sobremortalidad; en Ciudad Real, por ejemplo, los niveles de mortalidad fueron relativamente altos o muy altos en 1751-1752 y en 1785-1787 (Pérez, 1983, pp. 333-354). Aunque sorteemos el problema del cólera de 1855 obviando el censo de 1857 a favor del de 1860, el contraste entre la tasa de mortalidad atribuible a este y las calculadas para 1752 o 1787 puede incorporar un sensible sesgo al alza de la caída de la mortalidad entre la segunda mitad del setecientos y mediados del ochocientos.

Incluso teniendo presente lo anterior, en el cuadro 2 hemos plasmado las tasas de mortalidad hacia 1752, 1787, 1860 y 1887 en varias provincias, ${ }^{15}$ donde se pone de relieve la existencia de una pauta evolutiva en el largo plazo muy similar en todos los territorios castellanos aquí observados.

Aunque las cifras del cuadro 2 sobrevaloren el fenómeno, es incuestionable que la mortalidad hacia 1860 o hacia 1885 , en todas las provincias examinadas, era significativamente menor que la que se registraba en las mismas en la segunda mitad del siglo XVIII. Lamentablemente, estos datos, por razones ya esgrimidas, no posibilitan cuantificar con precisión tal descenso.

Aparte de intensas fluctuaciones interanuales, las defunciones también registraban importantes oscilaciones cíclicas. De ahí que los datos del cuadro 2 resulten claramente insuficientes para contrastar de forma adecuada la hipótesis de la caída de la mortalidad entre 1752 o 1787 y $1860 .{ }^{16}$ Las ratios finados-bautizados nos permitirán avanzar en tal cometido y nos ayudarán a desvelar las trayectorias en el mediano y largo plazos de la mortalidad en las distintas provincias.

\footnotetext{
${ }^{15}$ Las tasas de Ávila se han calculado con muestras de 35, 36, 33 y 39 pueblos para 1752, 1787, 1860 y 1887, respectivamente. Las de Burgos con muestras de 31, 38 y 38 núcleos de población para 1752, 1787 y 1860, respectivamente. Las de Guadalajara con muestras de 28, 29, 26 y 25 localidades para 1752, 1787, 1860 y 1887, respectivamente. En los casos de Albacete y Ciudad Real, todas las tasas estimadas se han realizado a partir de muestras de nueve y once núcleos, respectivamente, salvo para 1887 , en las que se han llevado a cabo con diez pueblos en el primero y con trece en el segundo.

${ }^{16} \mathrm{El}$ corte temporal de 1860 nos parece más adecuado para las comparaciones territoriales porque ninguna provincia padeció un episodio extraordinario de mortalidad en el intervalo 18561864. No obstante, somos conscientes de que las crisis formaban parte del "paisaje" habitual de la mortalidad en la España interior antes de 1815 o incluso de 1840.
} 
Am. Lat. Hist. Econ., año 22, núm. 3, septiembre-diciembre, 2015, pp. 108-144

\section{CUADRO 2. TASAS PROVINCIALES DE MORTALIDAD, AÑOS 1752, 1787, 1860 Y 1887 (EN \%0)}

\begin{tabular}{lrcccc}
\hline Años & Albacete & Ciudad Real & Burgos & Avila & Guadalajara \\
& & & & & \\
Hacia 1752 & - & 39.4 & 43 & 45.4 & 37.4 \\
Hacia 1787 & 37.4 & 44.4 & 39.9 & 38.2 & 43.6 \\
Hacia 1860 & 30.6 & 36.2 & 34 & 34.6 & 33.2 \\
Hacia 1887 & 33.4 & 31.3 & - & 34.9 & 33.3 \\
\hline
\end{tabular}

Fuentes: elaboración propia a partir de Camarero (1994); Martín (1985); Libros de lo Personal de las Respuestas Particulares del Catastro de Ensenada de las provincias de Ávila, Burgos, Guadalajara y Ciudad Real; Archivos Históricos Provinciales de Ávila y Ciudad Real, https:// familysearch.org, y Archivo de la Diputación de Burgos; Instituto Nacional de Estadística (1987, 1989a y 1989b); Censo de 1860 (1863); Nomenclátor de 1860 (1863); Censo de 1887 (1891); Libros de difuntos de los archivos diocesanos de Albacete, Ciudad Real, Burgos, Ávila y Sigüenza; https://familysearch.org

Mortalidad adulta, pároula y general

Comenzaremos examinando y comparando con otras provincias las ratios que pueden calcularse para todo el periodo que abarca esta investigación, los cocientes defunciones de adultos-bautizados en periodos de quince, 20, 25 o 50 años, que han quedado reflejados en el cuadro 3 y en la gráfica 1 .

A nuestro juicio, son tres las principales conclusiones que pueden inferirse de dichas ratios: a) en el largo plazo, la mortalidad adulta tendió a moderarse en todos los territorios aquí contemplados, situándose el retroceso del cociente defunciones de adultos-bautizados, de 1700-1749 a 1815-1864, entre un máximo de $30.2 \%$ en Ávila y un mínimo de $19.5 \%$ en Albacete; $b$ ) los niveles de mortalidad adulta tendieron a converger: la desviación típica de los logaritmos neperianos de las ratios descendió 33\% de 1700-1749 a 1815-1864 (convergencia sigma), de modo que los niveles de mortalidad adulta en las provincias de la España interior eran más parecidos en el siglo XIX que en la primera mitad del XVIII, y $c$ ) el movimiento a la baja de la mortalidad adulta se agotó en el transcurso del segundo cuarto del ochocientos.

Ese importante declive en el largo plazo de la mortalidad adulta fue interrumpido transitoriamente por su violentísimo repunte en la década y media inicial del siglo XIX (véanse Llopis, 2013; Pérez, 2010a): la ratio defunciones de adultos-bautismos se elevó, de 1750-1799 a 1800-1814, nada menos que $67.4 \%$ en Guadalajara, $61.6 \%$ en Burgos, $52.1 \%$ en Ciudad Real, 
CUADRO 3. PROMEDIOS DE LAS RATIOS DEFUNCIONES

DE ADULTOS BAUTIZADOS EN CINCO PROVINCIAS, 1700-1889

(PORCENTAJE)

\begin{tabular}{lccccc}
\hline Periodo & $\begin{array}{c}\text { Albacete } \\
\text { (catorce pueblos) }\end{array}$ & $\begin{array}{c}\text { Ciudad Real } \\
\text { (catorce pueblos) }\end{array}$ & $\begin{array}{c}\text { Burgos } \\
\text { (68 pueblos) }\end{array}$ & $\begin{array}{c}\text { Avila } \\
\text { (38 pueblos) }\end{array}$ & $\begin{array}{c}\text { Guadalajara } \\
\text { (29 pueblos) }\end{array}$ \\
1700-1724 & 44.5 & 46.2 & 45.2 & 47.6 & 50.1 \\
$1725-1749$ & 40.8 & 43.6 & 43.5 & 52.5 & 51.7 \\
$1750-1774$ & 37.1 & 40.4 & 40.5 & 43.1 & 41.7 \\
$1775-1799$ & 34.6 & 39.8 & 37.1 & 40.1 & 41.2 \\
$1800-1814$ & 52.7 & 61 & 62.7 & 59.5 & 69.3 \\
$1815-1839$ & 38.1 & 35 & 34.7 & 34.8 & 37.3 \\
$1840-1864$ & 30.6 & 30.9 & 33.8 & 35 & 38.2 \\
$1865-1889$ & 33.2 & 32.9 & - & 33.7 & 39 \\
$1700-1749$ & 42.6 & 44.9 & 44.4 & 50.0 & 50.9 \\
$1750-1799$ & 35.9 & 40.1 & 38.8 & 41.6 & 41.4 \\
$1815-1864$ & 34.3 & 33 & 34.3 & 34.9 & 37.8 \\
$1840-1889$ & 31.9 & 31.9 & - & 34.3 & 38.6 \\
\hline
\end{tabular}

Fuentes: elaboración propia con base en Llopis, Bernardos y Velasco (2015); base de datos de series vitales de Vanesa Abarca (2012) para la elaboración de su tesis doctoral; Libros de bautismos y defunciones de los archivos diocesanos de Albacete, Burgos y Ciudad Real; https:// familysearch.org

46.8\% en Albacete y 43.0\% en Ávila. Se trató, por tanto, de un cambio muy brusco en todos los territorios interiores.

Al comparar las trayectorias de las ratios defunciones de adultos-bautizados en Albacete y Ciudad Real, hallamos muchas similitudes hasta 1814; de hecho, los cocientes de lapsos de 25 años se movieron, hasta entonces, en la misma dirección y con intensidades no muy dispares. Sin embargo, la mortalidad adulta se comportó en Albacete de una manera singular en los 25 años posteriores al del final de la guerra de Independencia: la ratio finados adultos-bautizados superó en ese intervalo a la del periodo 1750-1799 en 6.1\%, en tanto que en Ciudad Real dicho cociente fue en 1815-1839 inferior en $12.7 \%$ al de la segunda mitad del siglo XVIII. ${ }^{17}$ Hasta 1814 la ratio óbitos de adultos-bautizados fue mayor en Ciudad Real que en Albacete; en cambio, después de esa fecha, la mortalidad de

\footnotetext{
${ }^{17}$ En Ávila, Burgos y Guadalajara, el nivel de la ratio óbitos de adultos-bautizados también fue claramente menor en 1815-1839 que en 1750-1799.
} 


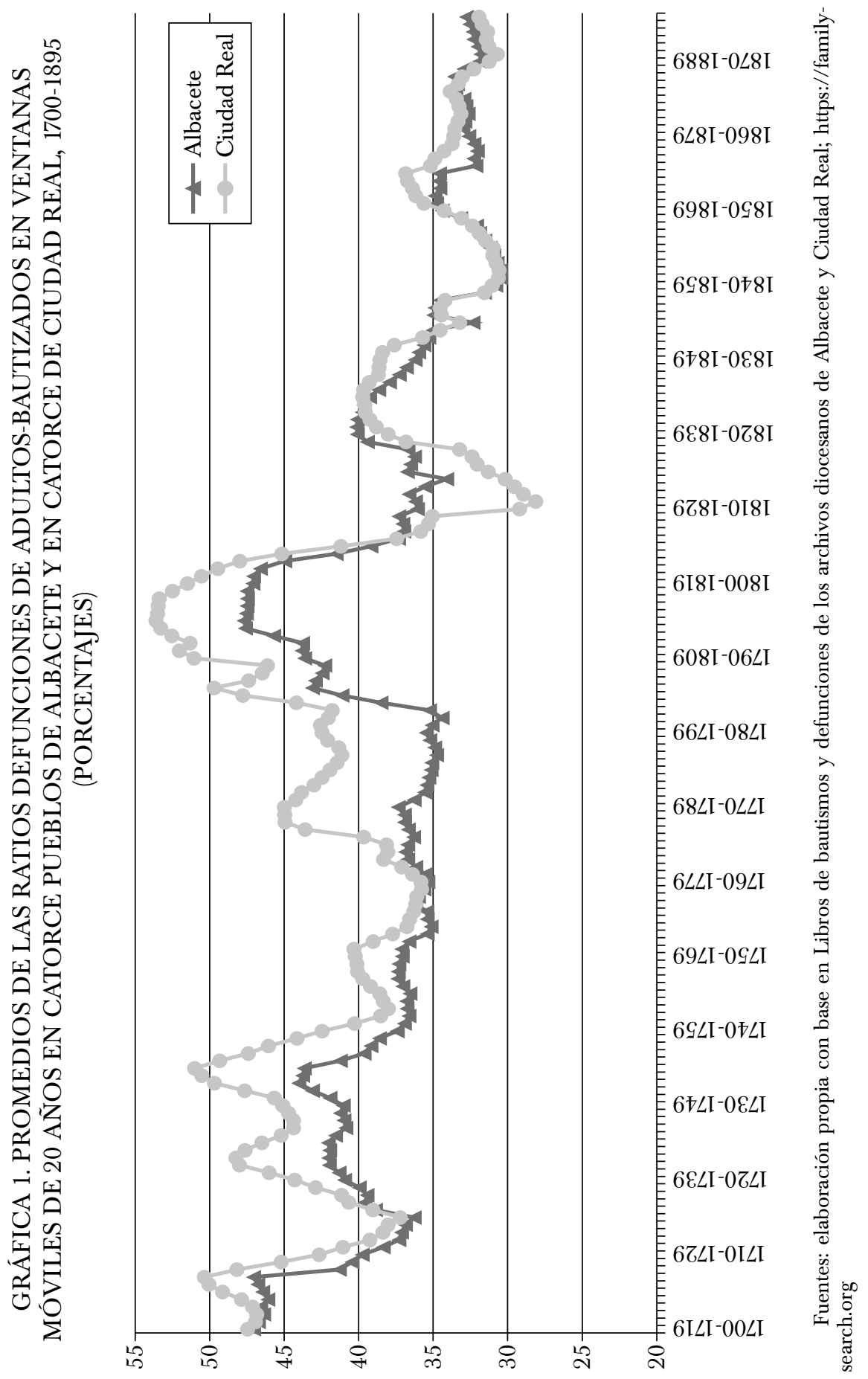


los mayores de ocho años alcanzó en la última provincia citada cotas más altas (1815-1839) o similares (1840-1889) a las de la primera.

Si por un momento prescindimos del lapso 1800-1814, el valor máximo de la ratio defunciones de adultos-bautizados se registró, en ambas provincias manchegas, en el primer cuarto del siglo XVIII; en Ciudad Real, el movimiento a la baja de ese cociente, al margen de lo sucedido a comienzos del ochocientos, si se consideran periodos de 25 años, fue ininterrumpido, mientras que, en Albacete, esa tendencia descendente también se quebró en el intervalo 1815-1839.

En suma, los registros sacramentales de Albacete y Ciudad Real apuntan a un importante declive de la mortalidad adulta en las dos provincias desde el segundo cuarto del siglo XVIII, si bien el descenso fue más contundente y menos interrumpido en la última, que partía de una ratio finados adultos-bautizados mayor que en la primera.

Ya se advirtió en el apartado de fuentes que en Ciudad Real y Albacete, como en muchos territorios de España meridional, los registros de óbitos no proporcionan un soporte documental suficiente para estudiar la evolución de la mortalidad párvula antes de mediados del siglo XVIII. Al respecto, la gráfica 2 avala que semejante estudio sí es posible hacerlo desde 1750: a) entre esta fecha y 1895, los porcentajes de los totales de finados que supusieron los óbitos de párvulos (54.8\% en Albacete y 54.2\% en Ciudad Real) fueron altos, y los promedios de 20 años siempre estuvieron por encima del $48 \%$ en ambos territorios, y $b$ ) los movimientos a largo plazo de estos últimos fueron muy similares, alcanzando en las dos provincias sus valores mínimos en los primeros compases del siglo XIX ${ }^{18}$ y sus valores máximos entre finales de la década de 1840 y finales de la de 1860 .

El cuadro 4 y la gráfica 3 incluyen la evolución de las ratios defunciones de párvulos-bautizados en muestras de localidades de cinco provincias castellanas y de Albacete y Ciudad Real, respectivamente.

La mortalidad infantil y juvenil se redujo bastante menos que la adulta en todos los territorios castellanos: del periodo 1750-1799 al periodo 18401889 , la ratio defunciones de párvulos-bautizados únicamente retrocedió 4.6\% en Albacete, 2.2\% en Ciudad Real, $8.2 \%$ en Ávila y 5.1\% en Guadalajara; en tanto que el cociente óbitos de adultos-bautizados disminuyó, entre esos mismos tramos, 11.1, 20.4, 17.5 y $6.8 \%$ en tales provincias, respectivamente. En Castilla, la fase que precedió a la transición demográfica se caracterizó por la fuerte resistencia a la baja de la mortalidad infantil y juvenil. Por otro lado, también los diferenciales de las ratios finados párvulos-bautizados de los distintos territorios tendieron a reducirse: el valor

\footnotetext{
${ }^{18}$ En las crisis de los albores del siglo XIX, lo mismo que en otras provincias, la elevación de la mortalidad adulta fue mayor o bastante mayor que la de la mortalidad párvula.
} 


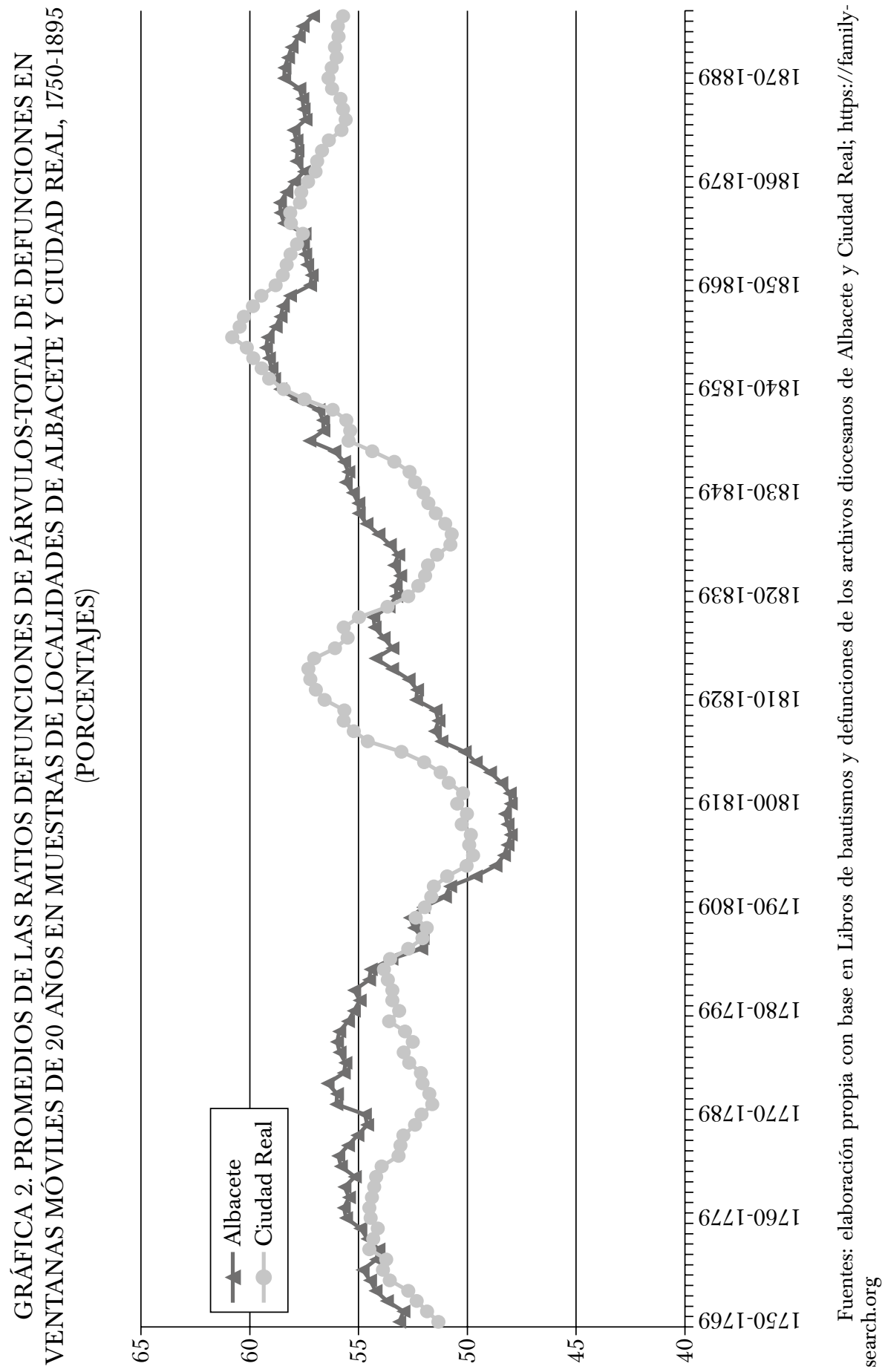


CUADRO 4. PROMEDIOS DE LAS RATIOS DEFUNCIONES DE PÁRVULOS-BAUTIZADOS EN CINCO PROVINCIAS, 1700-1889 (PORCENTAJE)

\begin{tabular}{|c|c|c|c|c|c|}
\hline Periodo & $\begin{array}{c}\text { Albacete } \\
\text { (nueve pueblos) }\end{array}$ & $\begin{array}{l}\text { Ciudad Real } \\
\text { (once pueblos) }\end{array}$ & $\begin{array}{c}\text { Burgos } \\
\text { (23 pueblos) }\end{array}$ & $\begin{array}{c}\text { Ávila } \\
\text { (22 pueblos) }\end{array}$ & $\begin{array}{l}\text { Guadalajara } \\
\text { (19 pueblos) }\end{array}$ \\
\hline $1700-1724$ & - & - & 51.2 & 48.8 & 48.7 \\
\hline $1725-1749$ & - & - & 53.5 & 53.4 & 48.6 \\
\hline $1750-1774$ & 46.1 & 44.8 & 50 & 48.6 & 45.6 \\
\hline $1775-1799$ & 45.0 & 46.1 & 48.8 & 48.4 & 49.3 \\
\hline $1800-1814$ & 46.5 & 52.6 & 57.0 & 63.0 & 58.8 \\
\hline $1815-1839$ & 41.5 & 39.3 & 44 & 43.6 & 45.4 \\
\hline $1840-1864$ & 42.8 & 44.1 & 45.3 & 43.8 & 44.1 \\
\hline 1865-1889 & 44.3 & 44.9 & - & 45.2 & 46.2 \\
\hline $1700-1749$ & - & - & 52.3 & 51.1 & 48.6 \\
\hline $1750-1799$ & 45.6 & 45.5 & 49.4 & 48.5 & 47.5 \\
\hline $1815-1864$ & 42.1 & 41.7 & 44.6 & 43.7 & 44.7 \\
\hline 1840-1889 & 43.5 & 44.5 & - & 44.5 & 45.1 \\
\hline
\end{tabular}

Fuentes: elaboración propia con base en Llopis, Bernardos y Velasco (2015); base de datos de series vitales de Vanesa Abarca (2012) para la elaboración de su tesis doctoral; Libros de bautismos y defunciones de los archivos diocesanos de Albacete, Burgos y Ciudad Real; https:// familysearch.org

máximo superaba al mínimo en tres puntos de 1750 a 1799 y sólo en 1.6 de 1840 a 1889.

Las trayectorias en el largo plazo de la mortalidad infantil y juvenil de los territorios castellanos examinados presentan más semejanzas que diferencias: $a$ ) el descenso de los promedios de las ratios defunciones de párvulos-bautizados, en todos ellos, entre 1750-1799 y 1815-1839 (9\% en Albacete, $13.6 \%$ en Ciudad Real, $10.9 \%$ en Burgos, $10.1 \%$ en Ávila y $4.4 \%$ en Guadalajara); b) una involución alcista de dicho cociente en los primeros quince años del siglo XIX, si bien mucho menos pronunciada en Albacete que en las demás provincias, y $c$ ) un repunte de tal ratio después de 1840, movimiento que tuvo especial intensidad en Ciudad Real. Estas similitudes en la trayectoria de la mortalidad infantil y juvenil en diversas provincias castellanas, entre mediados del siglo XVIII y finales del XIX, otorgan verosimilitud a la hipótesis de que la ratio defunciones de párvulos-bautizados, de 1700-1749 a 1750-1799, varió en Albacete y Ciudad Real de un modo parecido a como lo hizo en las otras tres provincias contempladas en el cuadro 4, descendiendo ligeramente. En consecuencia, es 


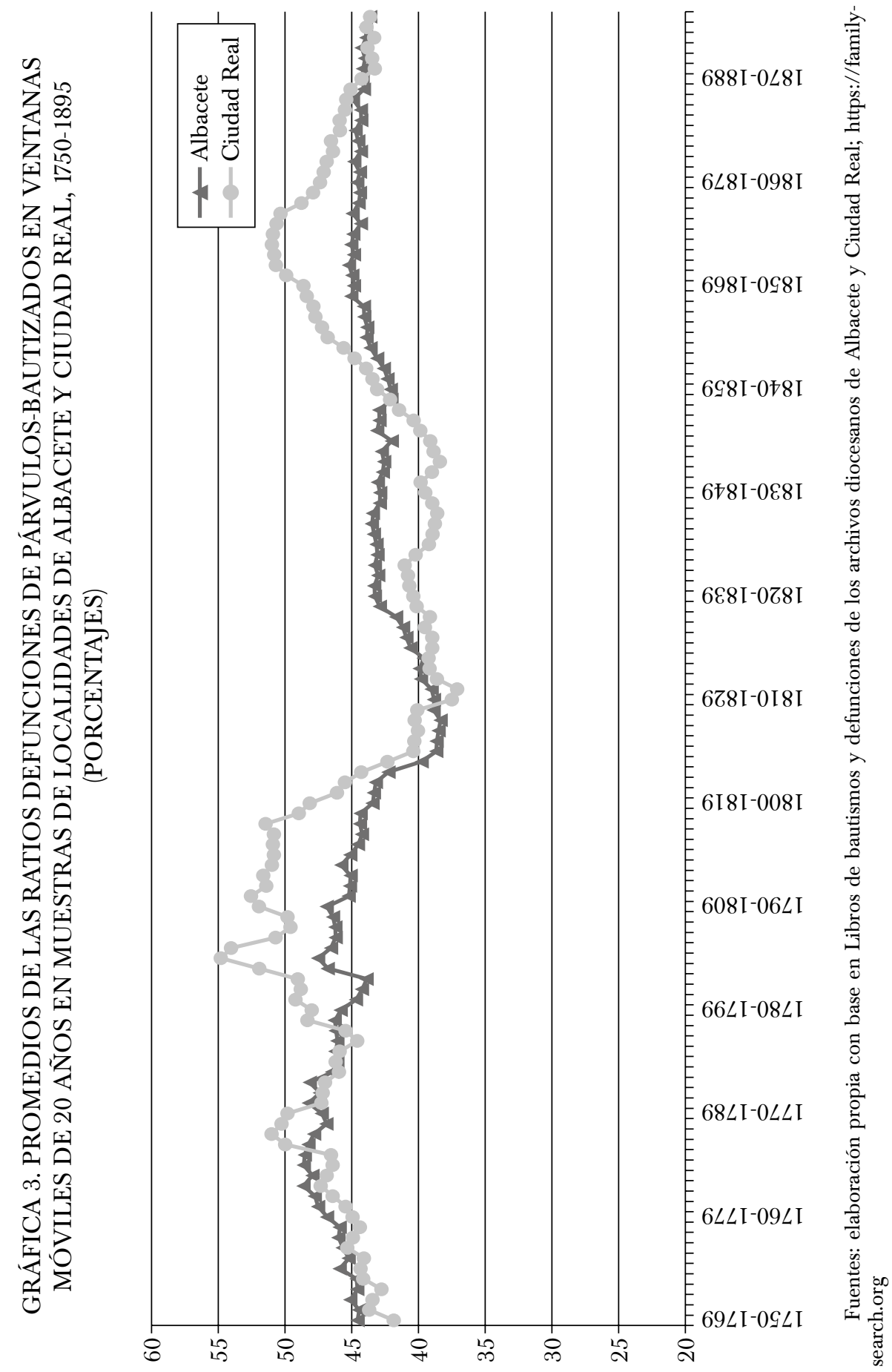


muy probable que la mortalidad párvula hubiese descendido en Albacete y Ciudad Real entre la primera mitad del setecientos y el intervalo 18401889 , pero en un porcentaje no superior a 10 por ciento.

El repunte de la mortalidad párvula en las décadas centrales del siglo XIX constituyó un fenómeno de alcance español y europeo (Perrenoud, 2001, pp. 73-77; Reher, Pérez y Bernabéu-Mestre, 1997, p. 42; Schofield y Reher, 1991), pero ese movimiento fue especialmente intenso y sobre todo duradero en los territorios castellanos: en estos, los niveles mínimos de la ratio óbitos de párvulos-bautizados no se recobraron hasta los años finales del siglo XIX o los primeros del XX.

La comparación de las mortalidades párvulas en Albacete y Ciudad Real arroja una importante semejanza y una gran diferencia. En lo que atañe a la primera, los niveles en el conjunto del periodo analizado fueron muy similares: de 1750 a 1895 , el promedio de las ratios óbitos de párvulos-bautizados ascendieron a 44.1 y $44.9 \%$ en Albacete y Ciudad Real, respectivamente. En cuanto a la segunda, la gráfica 3 apunta claramente a que los niveles de inestabilidad de la mortalidad infantil y juvenil fueron mucho mayores en Ciudad Real que en Albacete, fenómeno que en este artículo no es posible explicar.

En el cuadro 5 y en la gráfica 4 hemos reflejado la evolución de las ratios total de defunciones-bautizados en periodos de quince, 20, 25 o 50 años. Estas, que en los casos de Albacete y Ciudad Real se circunscriben al periodo 1750-1889, ponen de manifiesto que en el largo plazo la trayectoria de la mortalidad fue similar en todos los territorios aquí observados: de 1750-1799 a 1815-1864, el cociente total de defunciones-bautizados descendió 6.9\% en Albacete, 13.4\% en Ciudad Real, 11.4\% en Burgos, $12.3 \%$ en Ávila y $6.2 \%$ en Guadalajara. Después de 1860, la ratio óbitos-bautizados repuntó en todas las provincias: de 1840-1864 a 1865-1889, 7.3\% en Albacete, $8.9 \%$ en Ciudad Real, $2.4 \%$ en Ávila y $4.3 \%$ en Guadalajara. De modo que este movimiento involutivo de la mortalidad cobró mayor vigor en los territorios, más meridionales, de Castilla-La Mancha.

En los albores del siglo XIX, el ascenso de la mortalidad fue en Ciudad Real algo menor, y en Albacete bastante menor que en las demás provincias observadas: de 1750-1799 a 1800-1814, la ratio total de defuncionesbautizados aumentó $21.3 \%$ en la última, $32.8 \%$ en la primera, $38.7 \%$ en Ávila, 38.2\% en Burgos y 46\% en Guadalajara.

Puesto que la ratio defunciones totales-bautizados descendió entre 1700-1749 y 1815-1864 22.1\% en Ávila, 17.8\% en Guadalajara y 17.4\% en Burgos, que los cocientes óbitos de adultos-bautizados y óbitos de párvulos-bautizados evolucionaron en el largo plazo de forma no muy distinta en todas las provincias examinadas y que la mortalidad repuntó en todos ellas desde la década de 1860 , pero de manera especialmente intensa en 
Am. Lat. Hist. Econ., año 22, núm. 3, septiembre-diciembre, 2015, pp. 108-144

CUADRO 5. PROMEDIOS DE LAS RATIOS TOTAL DE DEFUNCIONESBAUTIZADOS EN CINCO PROVINCIAS, 1700-1889 (PORCENTAJES)

\begin{tabular}{|c|c|c|c|c|c|}
\hline Periodo & $\begin{array}{c}\text { Albacete } \\
\text { (nueve pueblos) }\end{array}$ & $\begin{array}{l}\text { Ciudad Real } \\
\text { (once pueblos) }\end{array}$ & $\begin{array}{c}\text { Burgos } \\
\text { (23 pueblos) }\end{array}$ & $\begin{array}{c}\text { Ávila } \\
\text { (22 pueblos) }\end{array}$ & $\begin{array}{c}\text { Guadalajara } \\
\text { (19 pueblos) }\end{array}$ \\
\hline $1700-1724$ & - & - & 93.2 & 95.6 & 99.2 \\
\hline $1725-1749$ & - & - & 94.0 & 104.6 & 99.4 \\
\hline $1750-1774$ & 84.7 & 85.7 & 89.8 & 89.8 & 85 \\
\hline $1775-1799$ & 79.9 & 86.4 & 84.5 & 88 & 89 \\
\hline $1800-1814$ & 99.8 & 114.3 & 120.5 & 123.3 & 127.0 \\
\hline 1815-1839 & 79.7 & 74.7 & 77.1 & 78.4 & 81.5 \\
\hline 1840-1864 & 73.5 & 74.4 & 77.6 & 77.6 & 81.6 \\
\hline 1865-1889 & 78.9 & 81 & - & 79.5 & 85.1 \\
\hline 1700-1749 & - & - & 93.6 & 100.1 & 99.3 \\
\hline 1750-1799 & 82.3 & 86.1 & 87.2 & 88.9 & 87 \\
\hline $1815-1864$ & 76.6 & 74.6 & 77.3 & 78 & 81.6 \\
\hline 1865-1889 & 76.2 & 77.7 & - & 78.6 & 83.4 \\
\hline
\end{tabular}

Fuentes: elaboración propia con base en Llopis, Bernardos y Velasco (2015); base de datos de series vitales de Vanesa Abarca (2012) para la elaboración de su tesis doctoral; Libros de bautismos y defunciones de los archivos diocesanos de Albacete, Burgos y Ciudad Real; https:// familysearch.org

las dos provincias manchegas, consideramos muy verosímil que la caída de la ratio total de defunciones-bautizados, de 1700-1749 a 1865-1889, se aproximase o superase ligeramente 10\% en Albacete y Ciudad Real. En suma, también en estas provincias más meridionales declinó de manera significativa la mortalidad entre la primera mitad del siglo XVIII y el intervalo 1865-1889. En este movimiento a la baja, al igual que en otros territorios castellanos, la moderación de la mortalidad adulta constituyó el elemento clave. Ahora bien, la tasa de mortalidad aún era elevada en la España interior a finales de la década de 1880, con valores provinciales todavía superiores a 30\% hacia 1887 (véase cuadro 2).

\section{Mortalidad ordinaria y extraordinaria}

La descomposición de las series de finados en difuntos ordinarios y difuntos extraordinarios puede ayudarnos a averiguar los factores determinantes de los movimientos de la mortalidad desde mediados del siglo XVIII. 


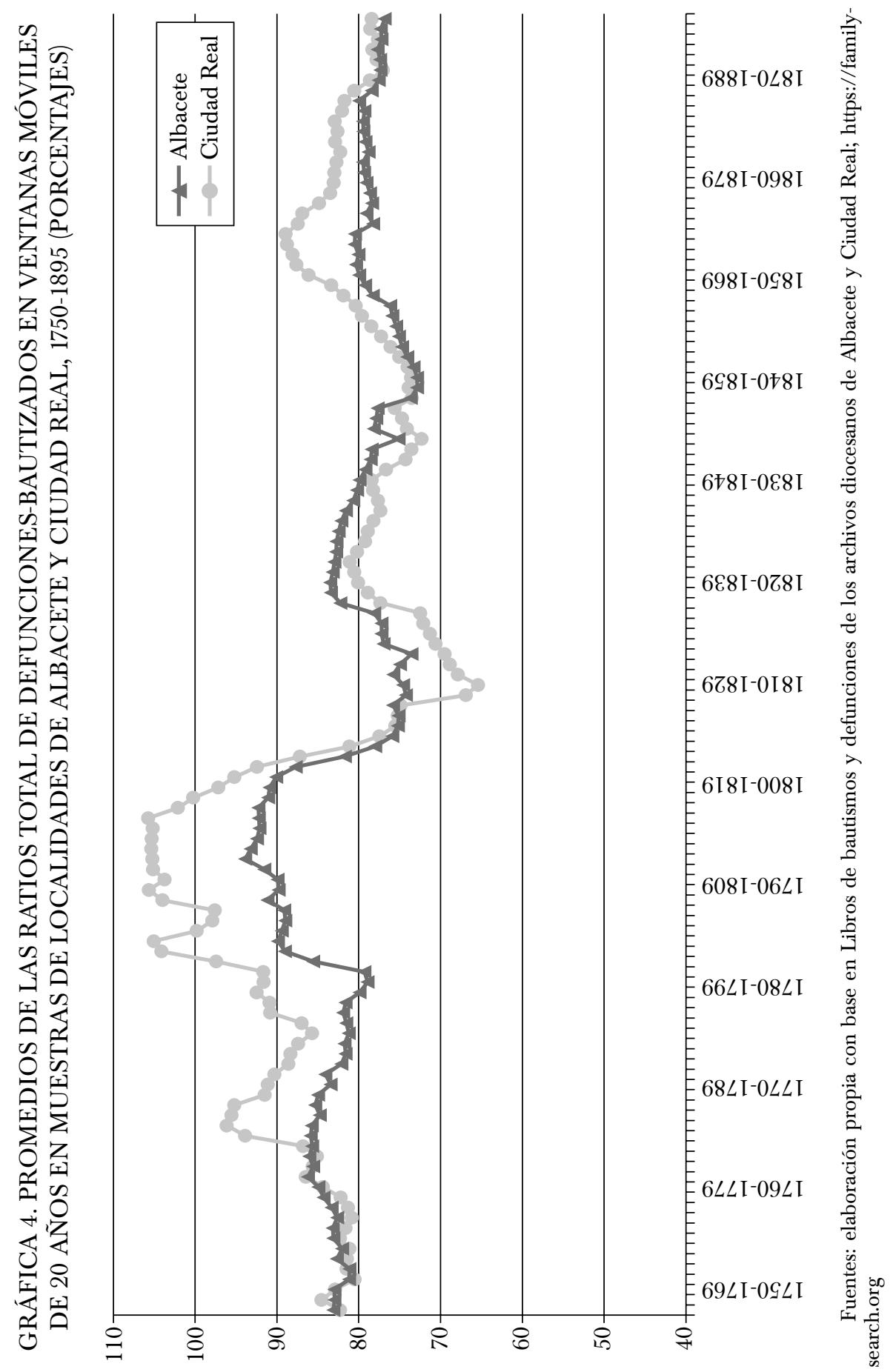


Nuestro propósito no estriba en la medición de la entidad y secuelas de las catástrofes demográficas en cada núcleo de población, sino en un ámbito provincial; por otro lado, consideramos que la probabilidad de que el número de óbitos se elevase por encima de un determinado porcentaje no es independiente del tamaño de las muestras de localidades objeto de estudio. De ahí que empleemos las series agregadas de finados de las muestras provinciales, y no las locales, para establecer los años de crisis y para medir las correspondientes sobremortalidades. Llopis y Abarca (2014) explican detalladamente los motivos de las opciones metodológicas adoptadas en la determinación de las crisis y en el cálculo de los índices sintéticos de mortalidad catastrófica. En cualquier caso, en este apartado se han seguido, en lo esencial, las directrices metodológicas establecidas por Flinn (1974) y Panta y Livi-Bacci (1977).

En los cuadros 6 y 7 hemos reflejado las trayectorias del peso relativo de las mortalidades catastrófica y ordinaria y las de las ratios defunciones extraordinarias-bautizados y defunciones ordinarias-bautizados. ${ }^{19}$

En el periodo para el que disponemos de registros completos de óbitos en todas las provincias (de 1750 a 1864), la mortalidad catastrófica supuso 5.6\% de la total en Albacete, $8.1 \%$ en Ciudad Real, $4.6 \%$ en Burgos, $5.9 \%$ en Ávila y 7.0\% en Guadalajara, datos que corroboran el predominio aplastante de la mortalidad ordinaria en el régimen demográfico antiguo, fenómeno ya indicado por Vicente Pérez Moreda (1980, pp. 16 y 471) hace más de tres décadas. Tal contribución sólo superó 10\% en el segundo cuarto del siglo XVIII y en la década y media inicial del XIX. La misma había disminuido sensiblemente entre la primera y la segunda mitad del setecientos en Ávila, Guadalajara y, sobre todo, Burgos, pero este movimiento descendente se quebró en los albores del ochocientos y no en todas las provincias se recuperó una vez concluida la guerra de Independencia; de hecho, en Albacete, Burgos y Guadalajara la contribución de la mortalidad catastrófica a la mortalidad total fue mayor de 1815 a 1864 que de 1750 a 1799. En cuanto al peso relativo de la mortalidad extraordinaria en la década y media inicial del ochocientos, resultó más moderado en Albacete y Ciudad Real que en las restantes provincias, lo que en buena medida obedeció a que las crisis de 1803 a 1805 y de 1812 a 1813 fueron, en estos territorios manchegos, menos virulentas que en Ávila, Burgos y Guadalajara. ${ }^{20}$ La moderación o desaparición de la mortalidad catastrófica

${ }^{19}$ Adviértase que en el cuadro 5 plasmamos los promedios anuales de las ratios defuncionesbautizados y en el cuadro 7 las ratios óbitos ordinarios y extraordinarios-bautizados. Se trata de dos cocientes distintos y, por consiguiente, el primero de ellos no tiene necesariamente que coincidir en todos los periodos con la suma de los dos últimos.

${ }^{20}$ Ahora bien, Ciudad Real registró una profunda crisis en 1809, con una sobremortalidad de 155.2 por ciento. 
CUADRO 6. CONTRIBUCIÓN DE LA MORTALIDAD CATASTRÓFICA A LA MORTALIDAD TOTAL EN CINCO PROVINCIAS CASTELLANAS, 1700-1889 (PORCENTAJES)

\begin{tabular}{|c|c|c|c|c|c|}
\hline Periodo & $\begin{array}{c}\text { Albacete } \\
\text { (nueve pueblos) }\end{array}$ & $\begin{array}{l}\text { Ciudad Real } \\
\text { (once pueblos) }\end{array}$ & $\begin{array}{c}\text { Burgos } \\
\text { (23 pueblos) }\end{array}$ & $\begin{array}{c}\text { Avila } \\
\text { (22 pueblos) }\end{array}$ & $\begin{array}{l}\text { Guadalajara } \\
\text { (19 pueblos) }\end{array}$ \\
\hline $1700-1724$ & - & - & 3.3 & 4 & 9.6 \\
\hline $1725-1749$ & - & - & 11.1 & 10.4 & 9.9 \\
\hline $1750-1774$ & 4.9 & 4.3 & 1 & 4.2 & 5.1 \\
\hline $1775-1799$ & 3.1 & 9.4 & 1.1 & 3.7 & 4.8 \\
\hline 1800-1814 & 13.1 & 18 & 17.7 & 17.4 & 18.1 \\
\hline 1815-1839 & 6.6 & 8 & 3.7 & 7.7 & 4.9 \\
\hline $1840-1864$ & 2.9 & 4.6 & 3.4 & 0 & 5.4 \\
\hline 1865-1889 & 2.2 & 2.7 & - & 0 & 0 \\
\hline $1700-1749$ & - & - & 7.4 & 7.5 & 9.7 \\
\hline $1750-1799$ & 4 & 7 & 1.1 & 4 & 4.9 \\
\hline $1815-1864$ & 4.7 & 6.2 & 3.6 & 3.1 & 5.1 \\
\hline 1840-1889 & 2.5 & 3.6 & - & 0 & 2.7 \\
\hline
\end{tabular}

Fuentes: elaboración propia con base en Llopis, Bernardos y Velasco (2015); base de datos de series vitales de Vanesa Abarca (2012) para la elaboración de su tesis doctoral; Libros de bautismos y defunciones de los archivos diocesanos de Albacete, Burgos y Ciudad Real; https:// familysearch.org

se produjo en algunas provincias en la década de 1840 y en otras después del cólera de 1855, pero todavía se registraron crisis a finales de la década de 1860 (Albacete) y en 1885 (Ciudad Real). Es probable que, tras la última fecha citada, las elevaciones de la mortalidad nunca más superasen $25 \%$ a escala provincial en España.

Del cuadro 6 también merece destacarse: a) de 1775 a 1799, la relativamente alta contribución de la mortalidad catastrófica a la mortalidad total en Ciudad Real debida a la fuerte intensidad de la crisis palúdica de 17851787 en dicha provincia, y b) de 1815 a 1839 ese mismo fenómeno, aunque no tan acentuado, en Albacete, Ciudad Real y Ávila, consecuencia de la magnitud que tuvieron los desastres demográficos de la década de 1830 en dichos territorios. $^{21}$

Los cocientes defunciones "extraordinarias"-bautizados y defunciones “ordinarias"-bautizados nos permitirán aproximarnos al papel que la mor-

${ }^{21}$ En Albacete se registraron importantes mortalidades en 1834 y 1838, mientras que Ávila padeció una profunda crisis en el trienio 1832-1834. 
Am. Lat. Hist. Econ., año 22, núm. 3, septiembre-diciembre, 2015, pp. 108-144

\section{CUADRO 7. RATIOS DEFUNCIONES "EXTRAORDINARIAS"- BAUTIZADOS Y DEFUNCIONES “ORDINARIAS"-BAUTIZADOS EN NUEVE PUEBLOS DE ALBACETE Y ONCE DE CIUDAD REAL, 1750-1889 (PORCENTAJES)}

\begin{tabular}{lcccc}
\hline \multirow{2}{*}{ Periodos } & \multicolumn{2}{c}{ Albacete } & \multicolumn{2}{c}{ Ciudad Real } \\
& $\begin{array}{c}\text { Defunciones } \\
\text { "extraordinarias"- } \\
\text { bautizados }\end{array}$ & $\begin{array}{c}\text { Defunciones } \\
\text { "ordinarias"- } \\
\text { bautizados }\end{array}$ & $\begin{array}{c}\text { Defunciones } \\
\text { "extraordinarias"- } \\
\text { bautizados }\end{array}$ & $\begin{array}{c}\text { Defunciones } \\
\text { "ordinarias"- } \\
\text { bautizados }\end{array}$ \\
$1750-1774$ & & & & \\
$1775-1799$ & 4.2 & 80.3 & 3.6 & 81.2 \\
$1800-1814$ & 2.5 & 77 & 8 & 76.8 \\
$1815-1839$ & 12.7 & 84.2 & 18 & 94.5 \\
$1840-1864$ & 5.1 & 72.9 & 5.9 & 67.4 \\
$1865-1889$ & 2.1 & 70.2 & 3.5 & 71.6 \\
$1750-1799$ & 1.7 & 75.6 & 2 & 73.7 \\
$1815-1864$ & 3.2 & 78.5 & 6 & 78.8 \\
$1840-1889$ & 3.5 & 71.4 & 4.6 & 69.6 \\
\hline
\end{tabular}

Fuentes: elaboración propia con base en Libros de bautismos y defunciones de los archivos diocesanos de Albacete y Ciudad Real; https://familysearch.org

talidad catastrófica desempeñó en los repuntes de la mortalidad general en la década y media inicial del ochocientos y en el intervalo 1865-1889, así como en el descenso de esta última tras la guerra de Independencia, que la situó en un nivel inferior al registrado en la segunda mitad del siglo XVIII, en las dos provincias de la meseta meridional aquí estudiadas (véase cuadro 7).

Del ascenso de las ratios finados totales-bautizados entre 1750-1799 y 1800-1814, la mortalidad catastrófica fue responsable de 62.5 y $43.3 \%$ en Albacete y Ciudad Real, respectivamente. Por consiguiente, en esta última provincia la fuerte elevación de la mortalidad "ordinaria" desempeñó un papel preponderante en el destrozo demográfico que tuvo lugar en los primeros quince años del siglo XIX.$^{22}$ En Albacete también se incrementó el cociente óbitos “ordinarios"-bautizados de 1800 a 1814, pero de manera bastante moderada, siendo en ella la mortalidad catastrófica el factor que marcó la adversa coyuntura demográfica en los albores del siglo XIX.

\footnotetext{
${ }^{22}$ No obstante, conviene tener presente que la frontera entre la mortalidad extraordinaria y la ordinaria es extensa y borrosa.
} 
En Albacete, toda la caída de la ratio total de finados-bautizados, de 1750-1799 a 1815-1864, obedeció a la disminución de la mortalidad "ordinaria", ya que la ratio óbitos "extraordinarios"-bautizados no sólo no retrocedió entre esos intervalos, sino que aumentó 9.4\%. Este incremento fue consecuencia de la notable entidad que tuvieron las crisis demográficas de la década de 1830 en el territorio albaceteño. En Ciudad Real, la mayor parte del declive del cociente total de óbitos-bautizados, entre esos mismos tramos, fue fruto de la moderación de la mortalidad "ordinaria": de los 10.6 puntos que aquel descendió entre esos dos intervalos, 9.2 fueron aportados por la ratio finados "ordinarios"-bautizados y sólo 1.4 por el cociente finados "extraordinarios"-bautizados. En definitiva, en los territorios meridionales de la región castellano-manchega el retroceso de la mortalidad, al menos entre la segunda mitad de siglo XVIII y la media centuria que siguió a la expulsión de los ejércitos napoleónicos, obedeció exclusiva o muy mayoritariamente a la moderación de la mortalidad ordinaria.

$\mathrm{El}$ incremento de la ratio óbitos-bautizados después de 1860 respondió al alza de la mortalidad ordinaria; de hecho, la catastrófica retrocedió (Albacete, Ciudad Real) o se mantuvo en el valor cero en 1865-1889; por consiguiente, las crisis de mortalidad tuvieron una contribución nula o negativa al incremento de la mortalidad general entre mediados de la década de 1860 y finales de la de 1880 .

En suma, las variaciones a mediano y largo plazos en los niveles de mortalidad general respondieron fundamentalmente a los cambios en las ratios defunciones "ordinarias"-bautizados. El descenso de estas fue la clave del declive de la mortalidad general tras la guerra de Independencia, de igual modo que su ascenso lo fue del repunte de aquella en el intervalo 1865-1889. La mortalidad catastrófica sólo desempeñó un papel importante o decisivo durante los calamitosos quince primeros años del siglo XIX.

\section{LAS RAZONES DEL DECLIVE DE LA MORTALIDAD}

Las fuentes empleadas en esta investigación nos han permitido realizar una aproximación razonable a la magnitud del declive de la mortalidad entre mediados del siglo XVIII y finales del XIX en Albacete y Ciudad Real y compararla con la observada en otras provincias castellanas (Burgos, Ávila y Guadalajara). Sin embargo, esa misma documentación arroja muy poca luz sobre los motivos de dicha moderación de la mortalidad. Por lo tanto, nos limitaremos a plantear algunas hipótesis al respecto, basadas en la literatura nacional e internacional.

Ni Albacete, ni Ciudad Real quedaron completamente al margen de la primera fase de la transición demográfica europea: como en otros muchos 
territorios del viejo continente, hacia 1750 se inició un movimiento a la baja de la mortalidad que se prolongó hasta la década de 1830, momento en que se inició una fase de estancamiento o ligero repunte de la misma (Perrenoud, 2001, pp. 65-67; Schofield y Reher, 1991). Ahora bien, el modelo del primer declive de la mortalidad en ambas provincias manchegas difirió sensiblemente del de otras zonas de Europa occidental en cuatro elementos básicos: su menor intensidad; la relativamente exigua aportación al mismo del aumento de la supervivencia de la población párvula; el fortísimo ascenso de la mortalidad en los primeros quince años del siglo XIX, y la magnitud y, sobre todo, la duración del movimiento involutivo de dicha variable después de 1860 .

Entre 1740-1754 y 1850-1864 la tasa de mortalidad cayó en Inglaterra de 28.2 a 22.2\% (21.3\%), en Suecia de 29.2 a 17.6\% (39.7\%) y en Francia de 38.6 a 23.4\% (39.4\%) (Chesnais, 1986, pp. 500-503 y 526-529; Wrigley y Schofield, 1981, pp. 532-534). De un lado, Inglaterra y Suecia registraban a mediados del setecientos niveles de mortalidad muy inferiores a los de la España interior; de otro, durante la segunda mitad del siglo XVIII y la primera del XIX, el retroceso de la mortalidad en Francia fue mucho mayor que el que conoció el interior castellano. $\mathrm{Y}$ en los tres países citados se produjo, de 1750 a 1865 , un proceso de convergencia entre sus tasas de mortalidad del que la España interior no participó.

La exigua caída de la ratio defunciones de párvulos-bautizados y varios estudios sobre el porcentaje de niños y jóvenes fallecidos en diferentes tramos de edad evidencian claramente la fuerte resistencia al descenso de la mortalidad infantil y juvenil en la España interior antes de 1890 (Reher, Pérez y Bernabéu-Mestre, 1997, p. 52; Sanz y Ramiro, 2002). En Ávila, Burgos y Guadalajara, de 1700-1749 a 1815-1864, el promedio de la ratio finados párvulos-bautizados descendió 14.5, 14.7 y 8\%, respectivamente; en cambio, el promedio del cociente óbitos de adultos-bautizados disminuyó 30.2, 22.7 y 25.7\%, en el mismo orden. Además, de 1865 a 1889, la mortalidad de los menores de ocho años parece haber sido en la España interior mayor que en el cuarto de siglo precedente..$^{23}$ En suma, las tasas de supervivencia de la población párvula sólo aumentaron de manera muy modesta entre los intervalos $1700-1749$ y $1865-1889 .{ }^{24}$

Por el contrario, en no pocos países europeos el notable aumento de las tasas de supervivencia de la población más joven contribuyó decisivamente al retroceso de la mortalidad en las últimas décadas del siglo XVIII y

\footnotetext{
${ }^{23}$ En Ávila y Guadalajara, los promedios de las ratios defunciones de párvulos/bautizados aumentaron, de 1840-1864 a 1865-1889, 3.2 y 4.8\%, respectivamente (véase cuadro 4).

${ }^{24}$ Sobre la mortalidad infantil en la España del siglo XIX, véase Reher, Pérez y BernabéuMestre (1997).
} 
en las primeras del XIX. Así, por ejemplo, de 1760-1769 a 1820-1829, la caída de la mortalidad entre los niños de uno a cuatro años fue de 35.3\% en Francia y de 32.8\% en Suecia; y la de los de cinco a catorce años alcanzó 35.6 y 37.6\%, respectivamente (Perrenoud, 2001, p. 69). Livi-Bacci (1988, p. 115) también considera que la prolongación de la duración media de la vida, en las últimas décadas del siglo XVIII y en las primeras del XIX, fue, ante todo, producto del retroceso de la mortalidad infantil y juvenil. Estos porcentajes son, sin duda, muy superiores a los que se estaban registrando por entonces en la España interior, aunque, de momento, no podamos precisar su cuantía.

Otra diferencia sustancial entre Europa y la España interior radicó en lo acontecido en la década y media inicial del ochocientos. En ningún país europeo hemos encontrado desastres demográficos de la magnitud de los que acaecieron en los territorios castellanos entre 1800 y 1814. Así, por ejemplo, de 1785-1799 a 1800-1814, las tasas promedio de mortalidad disminuyeron en Inglaterra $(2.3 \%)$ y en Suecia $(11.8 \%)$, y aumentaron ligeramente en Francia (6.7\%) (Chesnais, 1986; Wrigley y Schofield, 1981, pp. 532-534). En la España interior, en el mismo periodo, se registró una clara ruptura demográfica: el promedio de la ratio defunciones totales-bautizados creció 28, 23.2, 43.2, 36.9 y $41.1 \%$ en Albacete, Ciudad Real, Burgos, Ávila y Guadalajara, respectivamente. Esta brutal elevación fue consecuencia de las violentas crisis de 18031805,1809 y 1812-1813, pero también del sensible aumento en estos años de la mortalidad ordinaria. ${ }^{25}$

En los territorios castellanos, durante la primera fase de la transición demográfica, el fenómeno más destacado lo constituyó el descenso de la mortalidad adulta: de 1700-1749 a 1815-1864, el promedio del cociente óbitos de adultos-bautizados se contrajo en las cinco provincias citadas en porcentajes que oscilan entre cerca del 20 y algo más del 30\%. Son, pues, los factores determinantes de estas caídas los que hemos de intentar, cuando menos, atisbar.

Las condiciones medioambientales, el progreso económico (en especial, pero no en exclusiva, la mejora en la alimentación) y las medidas de salud pública han sido las causas más citadas para explicar el declive de la mortalidad en Europa entre mediados del siglo XVIII y las décadas centrales del XIX (Flinn, 1989; Kunitz, 1983; McKeown, 1978; Perrenoud, 2001; Schofield y Reher, 1991).

Perrenoud (2001, pp. 61, 71-72 y 82) ha enfatizado la primera de ellas: la coincidencia en el tiempo de la moderación de la mortalidad en espa-

${ }^{25}$ De 1775-1799 a 1800-1814, la ratio defunciones “ordinarias"-bautizados aumentó 9.4\% en Albacete, 23\% en Ciudad Real, 14.6\% en Burgos, 14.6\% en Ávila y 13.5\% en Guadalajara. 
cios con características socioeconómicas muy diversas induce a pensar que las fuerzas determinantes de aquella trascendían las fronteras nacionales y que las de índole ecológico o biológico fueron más relevantes que las de tipo socioeconómico. Subraya, en especial, la disminución de la diferencia térmica verano-invierno en los últimos compases del setecientos y los primeros del ochocientos. En cambio, el aumento de ese diferencial después de 1855 pudo haber contribuido al repunte de la mortalidad entre mediados del siglo XIX y la década de 1880 . Ahora bien, la cronología de ambos fenómenos no coincidió exactamente: el repunte (Alemania), estancamiento o desaceleración de la reducción de la mortalidad (Francia e Inglaterra, entre otros países) se inició en la década de 1830 o en la de 1840 (Chesnais, 1986, pp. 527-528), en tanto que la nueva tendencia ascendente del diferencial térmico verano-invierno ha sido datada hacia 1855 . En el caso de la España interior cabe añadir algo más: el fuerte ascenso de la mortalidad (de la extraordinaria y de la ordinaria) en los quince años iniciales del ochocientos, cuando, supuestamente, las condiciones biometeorológicas estaban favoreciendo el alza de las tasas de supervivencia de la población. En suma, aunque en absoluto negamos la influencia de las condiciones medioambientales en la trayectoria a mediano y largo plazos de la mortalidad entre comienzos del siglo XVIII y mediados del XIX en el interior castellano (asunto que está por investigar), consideramos que dicho factor no puede dar cuenta por sí solo de buena parte de los cambios registrados en dicha variable en ese periodo.

En la Europa del setecientos y de las primeras décadas del ochocientos, diversas medidas de salud pública contribuyeron al descenso de la mortalidad: la mayor eficiencia de los cordones sanitarios, las cuarentenas, la vacuna de Jenner, el drenaje de terrenos pantanosos, la mayor higiene de los ejércitos, el incremento de la disciplina militar y la reducción de los saqueos de las poblaciones (Flinn, 1974, p. 298; Kunitz, 1983, pp. 353-354; Perrenoud, 2001, p. 60). Sin embargo, los especialistas consideran que ni la medicina, ni las medidas higiénicas combatieron eficazmente la mayoría de los componentes de la mortalidad ordinaria en la España interior durante los siglos XVIII y XIX (Pérez, 1980, p. 467).

El tercer factor, el progreso económico, fue, a nuestro juicio, clave en el retroceso de la mortalidad registrada en la España interior en la segunda mitad del siglo XVIII y en las décadas posteriores al final de la guerra de Independencia (Llopis, 2010, 2012; Llopis y Sebastián, 2009; Sebastián, 2004). Se trató de dos impulsos económicos relativamente modestos en el espejo europeo, distintos y separados por una profunda depresión económica y demográfica en la década y media inicial del siglo XIX. Ahora bien, ciertas mejoras en el nivel de vida de la mayoría de la población castellana, aunque muy modestas, podrían haber sido suficientes para elevar de 
manera apreciable la capacidad de resistencia de esta a las enfermedades. Una pequeña mejora en el estatus nutricional neto podía generar, como han señalado recientemente Floud, Fogel, Harris y Hong (2011, pp. 1-15), un relevante círculo virtuoso: la nueva generación se tornaba algo más alta, pesada, saludable y longeva, lo que elevaba su capacidad laboral y posibilitaba un uso algo más intensivo de la fuerza de trabajo.

Antes de aludir brevemente a las transformaciones económicas del interior castellano en la segunda mitad del siglo XVIII y en la primera del XIX, quisiéramos subrayar un cambio relevante en la mortalidad europea del setecientos: entre las causas de defunción tendieron a ganar protagonismo las enfermedades cuyos resultados eran dependientes del estatus nutricional (Bengtsson, 2004, p. 44). Y la mortalidad adulta, la que, con gran diferencia, disminuyó en la España interior durante la primera fase de la transición demográfica europea, se hallaba más influida por las condiciones de acceso a los víveres esenciales que la mortalidad párvula. ${ }^{26}$

El balance económico de la España interior en la segunda mitad del siglo XVIII parece haber sido algo mejor del que hemos admitido. Las siguientes evidencias apuntan en esa dirección.

a) El saldo vegetativo del periodo 1750-1799 fue mucho mayor que el correspondiente a 1700-1749: el de 23 localidades burgalesas supuso 7.2\% de los bautismos en la primera mitad del setecientos y $13.4 \%$ en la segunda; el de 22 abulenses, 1 y 12\%, respectivamente, y el de 19 alcarreñas, 3.1 y $13.6 \%$, en igual orden. ${ }^{27}$ En una economía como la castellana de entonces, es muy poco verosímil que esta aceleración del crecimiento vegetativo no fuese acompañada de un impulso económico de cierta entidad.

b) En la segunda mitad del siglo XVIII, el crecimiento agrario fue significativamente mayor del que se infiere de las series decimales. Estas tienden a subestimarlo por tres motivos: a) desde 1761, la Hacienda Real administró directamente el excusado en varias fases en los obispados de la corona de Castilla, lo que entraña que los datos brutos decimales, caso de no homogeneizar las series estimando el peso relativo de la casa mayor dezmera de cada parroquia, introducen un sesgo a la baja en la medición del crecimiento agrario; las casas mayores dezmeras concentraban un porcentaje del producto agrario cercano o superior a $10 \%$ en diversos obispados (Barrio, 2004, p. 261; Pérez, 2009, p. 77); b) cada vez hay más evidencias documentales que apuntan a que la defraudación en el pago del diezmo aumentó en el último tercio del setecientos (sobre todo en las

\footnotetext{
${ }^{26}$ En esta última tenían gran peso las defunciones de niños menores de un año, que eran poco sensibles a las variaciones en las condiciones de acceso a los alimentos fundamentales.

${ }^{27}$ En los casos de Albacete y Ciudad Real, el deficiente registro de los óbitos de párvulos en la primera mitad del siglo XVIII hace imposible esta comparación.
} 
diócesis de la España meridional) más de lo que hemos venido señalando (Llopis y González, 2010, p. 21; Muñoz, 1994, pp. 155-165; Rodríguez, 1995, pp. 286-287; Robledo, 2002, pp. 211-213), y c) la documentación decimal sólo recogió en parte y tardíamente los frutos de la diversificación de los cultivos que parece haberse registrado en numerosas zonas. ${ }^{28}$

c) Se han acumulado testimonios que revelan modestos aumentos, en la segunda mitad del setecientos, en el uso del factor trabajo, incluso del femenino, y cierta diversificación de las actividades productivas (pequeña producción manufacturera, mayor explotación del monte, participación en el transporte, en el comercio al por menor y en el suministro de pequeños servicios) en las economías familiares de las zonas rurales de la España interior, sobre todo en áreas próximas a las ciudades y a los itinerarios de los principales circuitos mercantiles, lo que las tornó algo más resistentes frente a las adversidades económicas y las enfermedades, gracias a las nuevas fuentes de ingresos y a la mayor variedad de estos. ${ }^{29}$ Es bastante probable que el producto no agrario creciese significativamente más que el agrario en el mundo rural castellano de la segunda mitad del siglo XVIII.

d) Desde la década de 1760, la mejora de las infraestructuras viarias, las medidas liberalizadoras del tráfico de cereales y el desarrollo del comercio internacional contribuyeron a que los mercados funcionasen algo mejor, reduciéndose la volatilidad de los precios de los granos, tanto en el interior peninsular como en la periferia costera, ${ }^{30} \mathrm{al}$ menos hasta la guerra de la Convención (1793-1795). ${ }^{31}$ La moderación de las fluctuaciones interanuales de los precios del trigo en casi todos los mercados españoles entre comienzos del decenio de 1760 e inicios del de 1790, resultó muy apreciable (Llopis y Jerez, 2001; Llopis y Sotoca, 2005). No es sencillo determinar el grado de influencia de las variaciones en los niveles de inestabilidad de los precios de los víveres sobre la mortalidad general o adulta (véase, por ejemplo, Pérez, 2010b, pp. 181-218), pero es indiscutible que dicho factor

\footnotetext{
${ }^{28}$ Diversos testimonios, procedentes en especial de fondos catedralicios, sobre todo a partir de 1760 , revelan la firme resistencia de numerosos productores a satisfacer el diezmo de cultivos de reciente introducción, como la patata, o de otros de importancia marginal o muy secundaria hasta entonces.

${ }^{29}$ Un ejemplo leonés en Sebastián (2004, pp. 161-164). Una visión general en Sarasúa (2009) y Llopis (2012).

${ }^{30}$ Sobre el desarrollo mercantil en la España de la segunda mitad del siglo XVIII, y las mejoras en el funcionamiento de los mercados de granos, véanse Pérez Sarrión (2012) y Llopis y Sotoca (2005).

${ }^{31}$ Esta guerra contra la Francia revolucionaria abrió el aciago ciclo bélico de los años del cambio de siglo que, apenas con un respiro en 1803, enlazaría en 1808 con el inicio de la guerra de Independencia.
} 
no puede obviarse en los estudios relativos a esta variable demográfica en la etapa pretransicional. ${ }^{32}$

e) En España, como en otros países europeos, el mayor compromiso de las instituciones públicas en la lucha contra el hambre contribuyó a mitigar la falta de alimentos durante las agudas crisis frumentarias a un sector no irrelevante de la sociedad (Flinn, 1974, p. 311, y 1989, pp. 139-141). En este sentido, resulta muy ilustrativo el notable crecimiento de los pósitos en el interior castellano durante la segunda mitad del siglo XVIII (Anes, 1969, pp. 78-88).

En suma, en la España interior, desde mediados del setecientos, se registró una aceleración del crecimiento económico y, probablemente, una ligera elevación del PIB por habitante. Es cierto, sin embargo, que ello requirió de una cierta intensificación del factor trabajo y que fue acompañado de un aumento significativo de las desigualdades económicas, ya que las rentas territoriales aumentaron y la capacidad adquisitiva de los jornales menguó ${ }^{33}$ Ahora bien, en las dos Castillas, las familias que vivían exclusiva o casi exclusivamente de rentas salariales constituían una minoría y, además, algunas de ellas pudieron compensar en parte la caída de la retribución del factor trabajo aumentando el esfuerzo laboral de uno o de varios de sus miembros. ${ }^{34}$ En suma, la evolución de los jornales no es un buen indicador de los niveles de vida en sociedades marcadamente rurales donde el número de los pequeños productores superaba ampliamente al de los meros asalariados y donde la intensidad en el uso del factor trabajo registraba alteraciones de cierto relieve.

Tras las catástrofes demográficas y productivas de los primeros quince años del siglo XIX, la mortalidad volvió a descender, situándose en niveles inferiores, en mayor o menor medida, a los de la segunda mitad del siglo XVIII. Y este incremento de las tasas de supervivencia también coincidió con un nuevo impulso económico que hizo posible una cierta mejora en la dieta gracias a la espectacular expansión cerealista, al desarrollo del cultivo de la patata y a la distribución algo menos desigual del ingreso agrario fruto del aumento en la defraudación en el pago del diezmo (y de

\footnotetext{
${ }^{32}$ Sobre las relaciones entre fluctuaciones interanuales del precio del trigo y mortalidad en Castilla la Nueva, véase Reher (2004, pp. 26-31). Bengtsson, Campbell y Lee (2004) comparan los impactos de las carestías sobre las defunciones en varias comunidades rurales europeas y asiáticas.

${ }^{33}$ Sobre el aumento de la renta de la tierra, García Sanz (1977, pp. 296-310); Anes (1970, pp. 273-291); Álvarez Vázquez (1987, pp. 76-92); Sebastián (1990); Llopis (2002, pp. 132-134). Sobre el descenso de los salarios reales, Reher y Ballesteros (1993); Moreno Lázaro (2002, pp. 75-112); Llopis y García Montero (2011, pp. 304-307).

${ }_{34}$ Precisamente el deseo de muchas familias de pequeños productores y de asalariados de evitar la caída de sus ingresos, en un periodo en el que el crecimiento de las ciudades y del comercio estaba elevando, los requerimientos de mano de obra pudo inducirles a incrementar sustancialmente su oferta de trabajo, lo que intensificó el movimiento a la baja de los salarios reales.
} 
la reducción de su tasa durante el trienio liberal), de la moderación de las rentas territoriales y del mantenimiento de los salarios en niveles relativamente altos hasta la década de 1830 (Llopis, 2010, pp. 335-355 y 360-364; Pérez, 1980, p. 409). A partir de entonces se produjo un repunte de la mortalidad, originado por la primera guerra carlista y por las crisis acaecidas en ese decenio y luego, ya en las décadas centrales del siglo XIX, por el debilitamiento de las roturaciones, por el deterioro de las condiciones de acceso a la tierra para buena parte de la población rural y por el descenso de los salarios reales. En suma, por un nuevo e importante aumento de las desigualdades económicas (Llopis, 2010, pp. 363-366).

\section{CONCLusiones}

La tasa de mortalidad se mantuvo elevada en la España interior hasta las postrimerías del siglo XIX, pero los casos de Albacete y Ciudad Real corroboran la existencia de cambios significativos en el régimen demográfico del interior peninsular desde mediados del siglo XVIII. En Albacete y Ciudad Real, aunque la falta de registro o el subregistro de los óbitos de párvulos en los decenios iniciales del setecientos nos impidan ofrecer cifras precisas, todo apunta a que la mortalidad retrocedió, entre 1700-1749 y 1840-1889, cerca o algo más de 10\%. Fueron la moderación de la mortalidad adulta y la de la ordinaria las claves de tal descenso. En cuanto a la primera, el promedio de la ratio defunciones de adultos-bautizados disminuyó, de 1700-1749 a 1865-1889, 25.1\% en Albacete y 29\% en Ciudad Real, porcentajes de caída no muy distintos a los registrados en otras provincias castellanas en los mismos intervalos: $31.4 \%$ en Ávila y $24.2 \%$ en Guadalajara.

$\mathrm{Ni}$ en Albacete ni en Ciudad Real, a diferencia de lo ocurrido en Burgos, Ávila y Guadalajara, la mortalidad catastrófica retrocedió de manera importante en la segunda mitad del siglo XVIII (Llopis y Abarca, 2014). En los territorios más meridionales de Castilla-La Mancha, el descenso de la mortalidad general, al menos hasta los decenios centrales del siglo XIX, obedeció fundamentalmente a la mitigación de la mortalidad ordinaria.

En cuanto a las causas del declive de la mortalidad en los territorios de la España interior, nuestra visión de la historia económica del periodo nos induce a proponer la hipótesis de que fue la leve mejora en el nivel de vida de los castellanos, tanto durante la segunda mitad del siglo XVIII como después de la guerra de Independencia, el motivo esencial de dicha moderación.

Por último, cuando el caso de la España interior se coloca en el espejo europeo, conviene tener presente que hacia mediados del siglo XVIII España, y especialmente sus zonas interiores, presentaba una tasa de mor- 
talidad netamente superior a la que entonces registraba la mayoría de los territorios de la Europa septentrional y noroccidental; que hacia 1750, Francia exhibía unas cifras parecidas a las de España, pero la mortalidad, durante la segunda mitad del siglo XVIII y la primera del XIX, cayó en tierras galas de manera bastante más intensa que en la península (Francia convergió, en el ámbito de la mortalidad, con los países nórdicos y del mar del Norte, mientras que España no se aproximó a estos últimos), y que la mortalidad infantil y juvenil tuvo un comportamiento muy distinto en los territorios castellanos que en la mayor parte de las regiones de Europa occidental -en aquellos apenas declinó mientras que en estas el retroceso fue muy considerable y en no pocos casos constituyó, además, el factor de mayor enjundia en el aumento de la esperanza de vida durante la primera fase de la transición demográfica.

En cualquier caso, en la España interior, en el transcurso de los dos siglos que precedieron al comienzo de la transición demográfica se produjeron cambios importantes en la mortalidad. El principal, sin duda, fue el incremento significativo de las tasas de supervivencia de la población adulta.

\section{LISTA DE REFERENCIAS}

Abarca, V. (2012). La población de la provincia de Burgos, 1540-1857 (Trabajo final del máster en Economía). Universidad Complutense, Madrid.

Álvarez, J. A. (1987). Rentas, precios y crédito en Zamora en el Antiguo Régimen. Zamora: Colegio Universitario.

ANES, G. (1969). Economía e ilustración en la España del siglo XVIII. Barcelona: Ariel.

ANEs, G. (1970). Las crisis agrarias en la España moderna. Madrid: Taurus.

Arizcun, A. (1988). Economía y sociedad en un valle pirenaico del Antiguo Régimen. Baztán, 1600-1841. Pamplona: Gobierno de Navarra.

Barrio, M. (2004). El Real patronato y los obispos españoles del Antiguo Régimen (15561834). Madrid: Centro de Estudios Políticos y Constitucionales.

Bengtsson, T. (2004). Living standards and economic stress. En T. Bengtsson, C. CAMPBELl y J. Z. LeE, Life under pressure. Mortality and living standards in Europe and Asia, 1700-1900 (pp. 27-59). Cambridge, Massachusets: MIT Press.

Bengtsson, T., Campbell, C. y Lee, J. Z. (2004). Life under pressure. Mortality and living standards in Europe and Asia, 1700-1900. Cambridge, Massachusets: MIT Press.

Bernat, J. S. y Badenes, M. Á. (1988). Cronología, intensidad y extensión de las crisis demográficas en el País Valencià (siglos XVII-XIX). En C. PÉREZ (ed.), Estudis sobre la població del País Valencià (vol. I, pp. 537-557). Valencia: Ediciones Alfonso el Magnánimo/Instituto de Estudios Juan Gil-Albert.

Blanco, J. P. (1999): Demografía, familia y sociedad en la Extremadura moderna. Cáceres: Universidad de Extremadura. 
Am. Lat. Hist. Econ., año 22, núm. 3, septiembre-diciembre, 2015, pp. 108-144

Camarero, C. (ed.) (1994). Vecindario de Ensenada 1749 (4 vols.). Madrid: Tabapress.

CENSO DE 1857 (1858): Censo de la población de España según el recuento verificado el 21 de mayo de 1857 por la Comisión de Estadística General del Reino. Madrid, Imprenta Nacional.

CENSO DE 1860 (1863): Censo de la población de España según el recuento verificado en 25 de diciembre de 1860 por la Junta General de Estadística. Madrid, Imprenta Nacional.

CENSO DE 1887 (1891): Censo de la población de España según el empadronamiento hecho en 31 de diciembre de 1887. Madrid, Imprenta de la Dirección General del Instituto Geográfico y Estadístico.

Chesnais, J. C. (1986). La transition démographique. Etapes, formes, implications économiques. Étude de séries temporelles (1720-1984) relatives à 67 pays. París: Presses Universitaires de France.

FLINN, M. W. (1974). The stabilisation of mortality in preindustrial Western Europe. The Journal of European Economic History, 3(2), 285-318.

FuInN, M. W. (1989). El sistema demográfico europeo, 1500-1820. Barcelona: Crítica.

Floud, R., Fogel, R. W., Harris, B. y Hong, S. C. (2011). The changing body: Health, nutrition, and human development in the Western World since 1700. Cambridge: Cambridge University Press.

García, Á. (1977). Desarrollo y crisis del Antiguo Régimen en Castilla la Vieja. Economía y sociedad en tierras de Segovia, 1500-1814. Madrid: Akal.

GurríA, P. A. (2004). La población de La Rioja durante el antiguo régimen demográfico, 1600-1900. Logroño: Instituto de Estudios Riojanos.

Instituto Nacional de Estadística (1987). Censo de Floridablanca, 1787, vol. 2. Comunidades Autónomas de la Submeseta Sur. Madrid.

Instituto Nacional de Estadística (1989a). Censo de Floridablanca, 1787, vol. 3B. Comunidades Autónomas de la Submeseta Norte. Parte Occidental. Madrid.

Instituto Nacional de Estadística (1989b). Censo de Floridablanca, 1787, vol. 3A. Comunidades Autónomas de la Submeseta Norte. Parte Oriental. Madrid.

Kunitz, S. J. (1983). Speculations on the European mortality decline. The Economic History Review, 36(3), 349-364.

LANZA, R. (1991). La población y el crecimiento económico de Cantabria en el Antiguo Régimen. Madrid: Universidad Autónoma de Madrid/Universidad de Cantabria.

LÁZARO, M. y GurríA, P. A. (1989). Las crisis de mortalidad en La Rioja (siglos XVI-XVIII). Logroño: Instituto de Estudios Riojanos.

LIVI-BACCI, M. (1988). Ensayo sobre la historia demográfica europea: población y alimentación en Europa. Barcelona: Ariel.

LLOPIS, E. (2002). Otras caras "menos amables" de la agricultura española contemporánea. Historia Agraria, 28, 179-198.

LLOPIS, E. (2010). El impacto de la guerra de la Independencia en la agricultura española. En E. LA PARRA (ed.), La guerra de Napoleón en España. Reacciones, imágenes, consecuencias (pp. 333-378). Alicante: Universidad de Alicante/Casa de Velázquez. 
Llopis, E. (2012). España, 1750-1808: crecimiento, cambios y crisis. III Congreso Latinoamericano de Historia Económica. Simposio 24. Iberoamérica y España antes de las independencias: el impacto económico de las reformas ilustradas y de las guerras napoleónicas, San Carlos Bariloche, Argentina, 23-27 de octubre de 2012.

Llopis, E. (2013). La crisis del Antiguo Régimen, 1789-1840. En E. LlOPIS y J. MALUQUER (eds.), España en crisis. Las grandes depresiones económicas, $1348-2012$ (pp. 97-132). Barcelona: Pasado y Presente.

Llopis, E. y ABARCA, V. (2014). El retroceso de la mortalidad catastrófica y su papel en la moderación de la mortalidad general en la España interior en los siglos XVIII y XIX. IV CLADHE, Simposio 26, Las grandes crisis y depresiones demográficas y económicas en Iberoamérica y la península Ibérica, 1300-2013. Bogotá, 23-25 de julio.

Llopis, E., Bernardos, J. U. y Velasco, Á. L. (2015). ¿Pasó de largo por la España interior la primera fase de la transición demográfica? La mortalidad en Ávila y Guadalajara, 1700-1895. Investigaciones de Historia Económica, 11(2), 69-79.

Llopis, E. y GarCÍA, H. (2011). Precios y salarios en Madrid, 1680-1800. Investigaciones de Historia Económica, 7(2), 295-309.

LLOPIS, E. y GONZÁLEZ, M. (2010). Un crecimiento tempranamente quebrado: el producto agrario en Andalucía occidental en la Edad Moderna. Historia Agraria, 50, 13-42.

LLOPIS, E y Jerez, M. (2001). El mercado de trigo en Castilla y León, 1691-1788: Arbitraje espacial e intervención. Historia Agraria, 25, 13-68.

Llopis, E. y PÉREz, V. (2003). Evolución demográfica de la zona centro de España a través de los índices de bautismos, 1580-1850 (pp. 113-146). En VV. AA., Estudios de Historia y pensamiento económico. Homenaje al profesor Francisco Bustelo García del Real. Madrid: Editorial Complutense.

Llopis, E. y Sebastián, J. A. (2009). Impulso económico e inestabilidad: España, 18081850. En E. LlOPIS y C. MARICHAL (coords.), Latinoamérica y España, 1800-1850. Un crecimiento económico nada excepcional. Madrid y México: Marcial Pons/ Instituto de Investigaciones Dr. José María Luis Mora.

Llopis, E., Sebastián, J. A. y Velasco, Á. L. (2012). La debilidad demográfica de un territorio de la España interior. La población de Guadalajara, 1530-1860. Historia Agraria, 57, 13-45.

Llopis, E. y SotOcA, S. (2005). Antes, bastante antes: la primera fase de la integración del mercado español de trigo, 1725-1808. Historia Agraria, 36, 225-262.

Martín, M. (1985). Nuevos datos sobre un viejo problema: el coeficiente de conversión de vecinos en habitantes. Revista Internacional de Sociología, 43, 593-633.

McKeown, T. (1978). El crecimiento moderno de la población. Barcelona: Bosch (Colección Conjeturas).

Moreno, J. (2002). La harinería castellana y el capitalismo agrario en el tránsito a la industrialización, 1778-1868. Historia Agraria, 27, 165-189.

MuÑoz, M. D. (1994). Las resistencias al diezmo. En Hacienda pública española. Monografías, 1. El fraude fiscal en España (pp. 155-165). Madrid: Instituto de Estudios Fiscales. 
Am. Lat. Hist. Econ., año 22, núm. 3, septiembre-diciembre, 2015, pp. 108-144

Nomenclátor de 1857 (1858): Nomenclátor de los Pueblos de España formado por la Comisión de Estadística General del Reino en 1857. Madrid, Imprenta Nacional.

NomenClátOR DE 1860 (1863): Nomenclátor de los Pueblos de España formado por la Junta General de Estadística en 1860. Madrid, Imprenta Nacional.

Panta, L. Del y Livi-Bacci, M. (1977). Chronologie, intensité et diffusion des crises de mortalité en Italie: 1600-1850. Population, número spécial, 401-446.

PÉrez, E. (2009). Un mundo inmóvil. El producto agrícola por habitante en la cuenca alta del Duero durante la edad moderna. Investigaciones de Historia Económica, 14, 69-102.

PÉRez, G. (2012). La península comercial. Mercados, redes sociales y Estado en España en el siglo XVIII. Madrid: Marcial Pons.

PÉREZ, V. (1980). Las crisis de mortalidad en la España interior (siglos XVI-XIX). Madrid: Siglo XXI.

PÉREZ, V. (1983). Crisis demográficas y crisis agrarias: paludismo y agricultura en España a fines del siglo XVIII. En Congreso de Historia Rural. Siglos XV al XIX (pp. 333-354). Madrid: Universidad Complutense de Madrid.

PÉrez, V. (1984). La evolución de la población española desde finales del Antiguo Régimen. Papeles de Economía Española, 20, 20-38.

PÉrez, V. (2010a). Las crisis demográficas del periodo napoleónico en España. En E. LA PARra (ed.), La guerra de Napoleón en España. Reacciones, imágenes, consecuencias (pp. 305-332). Alicante: Universidad de Alicante/Casa de Velázquez.

PÉREZ, V. (2010b). Una nueva interpretación de las relaciones entre mortalidad y economía: pruebas históricas contra el modelo de "crisis de subsistencias". En S. CAVACIOCCHI (ed.), La interazioni fra economia e ambiente biologico nell'Europa preindustriale, secc. XIII-XVIII (pp. 181-218). Firenze: Firenze University Press.

Perrenoud, A. (2001). El retroceso de la mortalidad ordinaria. En J. P. Bardet y J. DUPÂQUIER (dirs.), Historia de las poblaciones europeas (pp. 59-82, vol. II. La revolución demográfica, 1750-1914). Madrid: Síntesis.

Piquero, S. (1991). Demografía guipuzcoana en el Antiguo Régimen. Bilbao: Universidad del País Vasco.

RAmiro, D. (1998). La evolución de la mortalidad en la España interior: 1785-1960 (Tesis doctoral inédita). Universidad Complutense de Madrid, Madrid.

Reher, D. S. (2001). España. En J. P. BARdet y J. DupÂQuier (dirs.), Historia de las poblaciones europeas (vol. II. La revolución demográfica, 1750-1914). Madrid: Síntesis.

REHER, D. S. (2004). Fluctuaciones de precios, integración de mercados y bienestar de la población en Castilla, siglos XVII-XX. Reflexiones en honor a Nicolás SánchezAlbornoz. En C. E. Lida y J. A. PIQUeras (comps.), Impulsos e inercias del cambio económico. Ensayos en honor a Nicolás Sánchez-Albornoz (pp. 19-39). Valencia: Centro Francisco Tomás y Valiente/Fundación Instituto de Historia Social.

Reher, D. S. y Ballesteros, E. (1993). Precios y salarios en Castilla la Nueva, 15011991. Revista de Historia Económica, 11(1), 101-151. 
Reher, D. S., Pérez, V. y Bernabéu-Mestre, J. (1997). Assessing change in historical contexts. Childhood mortality in Spain during the demographic transition. En C. A. Corsini y P. P. Viazzo (eds.), The decline of infant and child mortality. The European experience: 1750-1900 (pp. 34-56). Países Bajos: The Hague/Martinus/Nijhoff Publishers/UnicEF.

Robledo, R. (2002). Nuevas y viejas cuestiones en la historia agraria española. Ayer, $47,261-275$.

Rodríguez, C. M. (1995). Algunas consideraciones sobre la reforma del clero regular en España (1800-1808). Espacio, tiempo y forma. Serie IV, Historia moderna, 8, 303-318.

Rodríguez, C. (1995). La crisis del Antiguo Régimen en el arzobispado de Toledo. El impago de diezmos (1800-1820). En J. M. DonÉZAr y M. PÉrez (eds.), Antiguo Régimen y liberalismo. Homenaje a Miguel Artola: Vol. 2. Economía y sociedad (pp. 285293). Madrid: Alianza Editorial/Universidad Autónoma de Madrid.

SAAVEdRA, P. (1985). Economía, política y sociedad en Galicia: La provincia de Mondoñedo, 1480-1830. Madrid: Xunta de Galicia.

SaAvedra, P. (1996). Das casas de morada ó monte comunal. Santiago de Compostela: Xunta de Galicia.

SANZ, A. (1997). La transición de la mortalidad infantil y juvenil en el Madrid rural. Siglos XIX y XX (Tesis doctoral inédita). Universidad Complutense de Madrid, Madrid.

SANZ, A. y Ramiro, D. (2002). Infancia, mortalidad y niveles de vida en la España interior, siglos XIX y XX. En J. M. MARTínEZ (ed.), El nivel de vida en la España rural, siglos XVIII-XX (pp. 359-403). Alicante: Universidad de Alicante.

SARASÚA, C. (2009). Working harder but still poor. The "industrious revolution" in 18th century Spain. XVth World Economic History Congress, Session Industrious Women and Children of the World? Jan de Vries 'Industrious Revolution' as Conceptual Tool for Researching Women's and Children's Work in an International Perspective, Utrecht.

SCHOFIELD, R. y REHER, D. S. (1991). The decline of mortality in Europe. En R. SCHOFIELD, D. S. REHER y A. BIDEAU (eds.), The decline of mortality in Europe (pp. 1-17). Oxford: Oxford University Press.

Sebastián, J. A. (1990). La renta de la tierra de León durante la edad moderna. Primeros resultados y algunas reflexiones a partir de fuentes monásticas. Revista de Historia Económica, 1(8), 53-80.

SEbastín, J. A. (2004). La agricultura española y el legado del Antiguo Régimen (1780-1855). En E. Llopis (ed.), El legado económico del Antiguo Régimen en España (pp. 147-186). Barcelona: Crítica.

VALLIN, J. (1991). Mortality in Europe from 1720 to 1914: Long-term trends and changes in patterns by age and sex. En R. Schofield, D. S. Reher y A. BideAu (eds.), The decline of mortality in Europe (pp. 38-67). Oxford: Oxford University Press.

Wrigley, E. A. y SCHOFIELD, R. S. (1981). The population history of England, 1541-1871: A reconstruction. Cambridge: Cambridge University Press. 